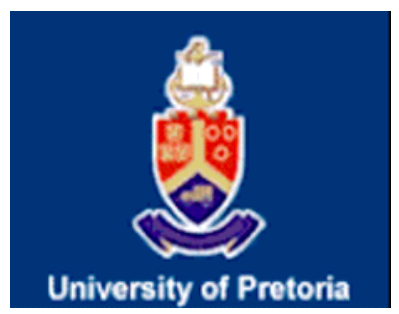

University of Pretoria

Department of Economics Working Paper Series

\author{
Predicting Downturns in the US Housing Market: A Bayesian \\ Approach \\ Rangan Gupta \\ University of Pretoria \\ Sonali Das \\ CSIR \\ Working Paper: 2008-21 \\ June 2008
}

Department of Economics

University of Pretoria

0002, Pretoria

South Africa

Tel: +27 124202413

Fax: +27 123625207 


\title{
PREDICTING DOWNTURNS IN THE US HOUSING MARKET: A BAYESIAN APPROACH
}

RANGAN GUPTA* AND SONALI DAS $^{* *}$

\begin{abstract}
This paper estimates Bayesian Vector Autoregressive (BVAR) models, both spatial and non-spatial (univariate and multivariate), for the twenty largest states of the US economy, using quarterly data over the period 1976:Q1 to 1994:Q4; and then forecasts one-to-four quarters ahead real house price growth over the out-of-sample horizon of 1995:Q1 to 2006:Q4. The forecasts are then evaluated by comparing them with the ones generated from an unrestricted classical Vector Autoregressive (VAR) model and the corresponding univariate variant the same. Finally, the models that produce the minimum average Root Mean Square Errors (RMSEs), are used to predict the downturns in the real house price growth over the recent period of 2007:Q1 to 2008:Q1. The results show that the BVARs, in whatever form they might be, are the best performing models in 19 of the 20 states. Moreover, these models do a fair job in predicting the downturn in 18 of the 19 states, however, they always under-predict the size of the decline in the real house price growth rate - an indication of the need to incorporate the role of fundamentals in the models.
\end{abstract}

JEL Classification: E17, E27, E37, E47.

Keywords: BVAR Model; BVAR Forecasts; Forecast Accuracy; SBVAR Model; SBVAR Forecasts; VAR Model; VAR Forecasts.

\section{INTRODUCTION}

This paper estimates Bayesian Vector Autoregressive (BVAR) models, both spatial and non-spatial (univariate and multivariate), for the twenty largest states (in terms of population) of the US economy ${ }^{1}$, using quarterly data over the period 1976:Q1 to 1994:Q4; and then forecasts one-to-four quarters ahead real house price growth over the 48 quarters out-of-sample forecast horizon of 1995:Q1 to 2006:Q4. The forecasts are then evaluated by comparing them with the ones generated from an unrestricted classical Vector Autoregressive (VAR) model and the corresponding univariate variant the same. Finally, the models that produce the minimum average Root Mean Square Errors (RMSEs), or in other words the "optimal” models, are used to predict the downturns in the real house price growth over the recent period of 2007:Q1 to 2008:Q1.

House price downturn in the last few quarter has been of concern in the US housing market. After an initial boom in the late 1990s, and even into the early 2000s, activity in the US housing market has of late waned (NAR, 2006). Booms and busts in house prices can have significant impact on the confidence of consumer expenditure, and, in turn, on the financial markets. Stock and Watson (2003) pointed to the role of asset prices in forecasting inflation, and have highlighted the dominance of house prices in this regard. Thus, a concern to all stakeholders is whether the growth in house prices is predictable. As such, the need to design models that can forecast house prices timely, and their possible turns, is of paramount importance. In this regard, the VARs, simply based on the variables of interest, which in our case are the real house price growths of the twenty largest US states, could be of tremendous value. Even though these models lack information about the possible fundamentals that might be affecting the housing market, they can be very handy when it comes to providing preliminary indication about where the variables of interest might be heading (Gupta and Das (2008) and Das et al. (2008)). The fact that VARs, especially BVARs, are quite well-suited in predicting turning points of macroeconomic variables have recently been substantiated by Dua and Ray (1995), Dua and Miller (1996), Del Negro (1999), Gupta and Sichei (2006), Gupta (2006, 2007a), Zita and Gupta (2007) and Banerji et al. (2008), amongst others. Moreover, as indicated by Rapach and Strauss (2007, 2008), Gupta and Das (2008) and Das et al. (2008), it is also important to account for the effects of the house price of neighbouring states in predicting the house price of a specific state and herein lies the rationale for using spatial BVAR (SBVAR) models, over and above the standard VAR and BVAR models based

\footnotetext{
* Corresponding author. Contact Details: Associate Professor, Department of Economics, University Of Pretoria, Pretoria, 0002, South Africa. Phone: +27 12420 3460, Fax: +27 12362 5207, Email: Rangan.Gupta@up.ac.za.

${ }^{* *}$ Senior Researcher, Logistics and Quantitative Methods, CSIR Built Environment, P.O. Box: 395, Pretoria, 0001, South Africa. Phone: +27 12841 3713, Fax: +27 12841 3037, Email: SDas@csir.co.za.

${ }^{1}$ Based on the 2000 census, these states, in alphabetical order, are: Arizona (AZ), California (CA), Florida (FL), Georgia (GA), Illinois (IL), Indiana (IN), Massachusetts (MA), Maryland (MD), Michigan (MI), Missouri (MO), North Carolina (NC), New Jersey (NJ), New York (NY), Ohio (OH), Pennsylvania (PA), Tennessee (TN), Texas (TX), Virginia (VA), Washington (WA) and Wisconsin (WI).
} 
on the Minnesota priors ${ }^{2}$, for forecasting house price.

To the best of our knowledge, this is the first attempt to predict the recent downturns in the real house price growth for the twnety largest states of the US economy. The remainder of the paper is organized as follows: Section 2 outlines the details of the structure and the estimation of the VAR, BVARs and the SBVAR comprising of the real house price growth of the twenty largest US states, while Section 3 discusses the layout of the models. Section 4 compares the accuracy of the out-ofsample forecasts generated from the alternative models, and Section 5 is devoted to analyzing the ability of the "optimal" model ${ }^{3}$ to predict the turning point in the real house price growth. Finally, Section 6 concludes and considers possible areas of future research by highlighting the limitations of this study.

\section{VARs, BVARs AND SBVAR: SPECIFICATION AND ESTIMATION ${ }^{4}$}

The Vector Autoregressive (VAR) model, though 'atheoretical', is particularly useful for forecasting purposes. An unrestricted VAR model, as suggested by Sims (1980), can be written as follows:

$$
y_{t}=A_{0}+A(L) y_{t}+\varepsilon_{t}
$$

where $y$ is a $(n \times 1)$ vector of variables being forecasted; $A(L)$ is a $(n \times n)$ polynomial matrix in the backshift operator $L$ with lag length $p$, i.e., $A(L)=A_{1} L+A_{2} L^{2}+\ldots \ldots \ldots \ldots \ldots . . .+A_{p} L^{p} ; A_{0}$ is a $(n \times 1)$ vector of constant terms, and $\varepsilon$ is a $(n \times 1)$ vector of error terms. In our case, we assume that $\varepsilon \sim N\left(0, \sigma^{2} I_{n}\right)$, where $I_{n}$ is a $n \times n$ identity matrix .

Note the VAR model generally uses equal lag length for all the variables of the model. A drawback of VAR models is that many parameters need to be estimated, some of which may be insignificant. This problem of overparameterization, resulting in multicollinearity and a loss of degrees of freedom, leads to inefficient estimates and possibly large out-of-sample forecasting errors. One solution often adapted, is simply to exclude the insignificant lags based on statistical tests. Another approach is to use a near VAR, which specifies an unequal number of lags for the different equations.

However, an alternative approach to overcoming this overparameterization, as described in Litterman (1981), Doan et al (1984), Todd (1984), Litterman (1986), and Spencer (1993), is to use a Bayesian VAR (BVAR) model. Instead of eliminating longer lags, the Bayesian method imposes restrictions on these coefficients by assuming that they are more likely to be near zero than the coefficients on shorter lags. However, if there are strong effects from less important variables, the data can override this assumption. The restrictions are imposed by specifying normal prior distributions with zero means and small standard deviations for all coefficients with the standard deviation decreasing as the lags increase. The exception to this is that the coefficient on the first own lag of a variable has a mean of unity. Litterman (1981) used a diffuse prior for the constant. This is popularly referred to as the 'Minnesota prior' due to its development at the University of Minnesota and the Federal Reserve Bank at Minneapolis.

Formally, as discussed above, the means and variances of the Minnesota prior take the following form:

$$
\beta_{i} \sim N\left(1, \sigma_{\beta_{i}}^{2}\right) \text { and } \beta_{j} \sim N\left(0, \sigma_{\beta_{j}}^{2}\right)
$$

where $\beta_{i}$ denotes the coefficients associated with the lagged dependent variables in each equation of the VAR, while $\beta_{j}$ represents any other coefficient. In the belief that lagged dependent variables are important explanatory variables, the prior means corresponding to them are set to unity. However, for all the other coefficients, $\beta_{j}$ 's, in a particular equation of the VAR, a prior mean of zero is assigned to suggest that these variables are less important to the model.

\footnotetext{
${ }^{2}$ See Section 2 for further details.

${ }^{3}$ A model is said to be optimal if it on average produces the minimum value for the specific statistic measuring the out-of-sample forecast performance. See Section 3 and 4 for further details.

${ }^{4}$ The discussion in this section relies heavily on LeSage (1999), Gupta and Sichei (2006), Gupta (2006, 2007), Gupta and Das (2008) and Das et al. (2008).
} 
The prior variances $\sigma_{\beta_{i}}^{2}$ and $\sigma_{\beta_{j}}^{2}$, specify uncertainty about the prior means $\bar{\beta}_{i}=1$, and $\bar{\beta}_{j}=0$, respectively. Because of the overparameterization of the VAR, Doan et al. (1984) suggested a formula to generate standard deviations as a function of small numbers of hyperparameters: $w, d$, and a weighting matrix $f(i, j)$. This approach allows the forecaster to specify individual prior variances for a large number of coefficients based on only a few hyperparameters. The specification of the standard deviation of the distribution of the prior imposed on variable $j$ in equation $i$ at lag $m$, for all $i, j$ and $m$, defined as $S_{1}(i, j, m)$, can be specified as follows:

$$
S_{1}(i, j, m)=[w \times g(m) \times f(i, j)] \frac{\hat{\sigma}_{j}}{\hat{\sigma}_{i}}
$$

with $f(i, j)=1$, if $i=j$ and $k_{i j}$ otherwise, with $\left(0 \leq k_{i j} \leq 1\right) ; g(m)=m^{-d}, d>0$. Note that $\hat{\sigma}_{i}$ is the estimated standard error of the univariate autoregression for variable $i$. The ratio $\hat{\sigma}_{i} / \hat{\sigma}_{j}$ scales the variables to account for differences in the units of measurement and, hence, causes specification of the prior without consideration of the magnitudes of the variables. The term $w$ indicates the overall tightness and is also the standard deviation on the first own lag, with the prior getting tighter as we reduce the value. The parameter $g(m)$ measures the tightness on lag $m$ with respect to lag 1 , and is assumed to have a harmonic shape with a decay factor of $d$, which tightens the prior on increasing lags. The parameter $f(i, j)$ represents the tightness of variable $j$ in equation $i$ relative to variable $i$, and by increasing the interaction, i.e., the value of $k_{i j}$, we can loosen the prior. ${ }^{5}$

In the literature, the values of overall tightness $(w)$ are $0.1,0.2$, while those of the lag decay $(d)$ are 1.0 and 2.0, with $k_{i j}=0.5$, which implies a weighting matrix $(F)$ of the following form:

$$
F=\left[\begin{array}{cccccc}
1.0 & 0.5 & . & . & . & 0.5 \\
0.5 & 1.0 & . & . & . & 0.5 \\
\cdot & . & . & . & . & . \\
\cdot & . & . & . & . & . \\
\cdot & . & . & . & . & . \\
0.5 & . & . & . & . & 1.0
\end{array}\right]
$$

Since, the lagged dependant variable in each equation is thought to be important, $F$ imposes $\bar{\beta}_{i}=1$ loosely, while, given that the $\beta_{j}$ coefficients are associated with variables presumed to be less important, the weighting matrix $F$ imposes the prior means of zero more tightly on the coefficients of the other variables in each equation. Given that the Minnesota prior treats all variables in the VAR, except for the first own-lag of the dependent, in an identical manner, quite a few number of attempts

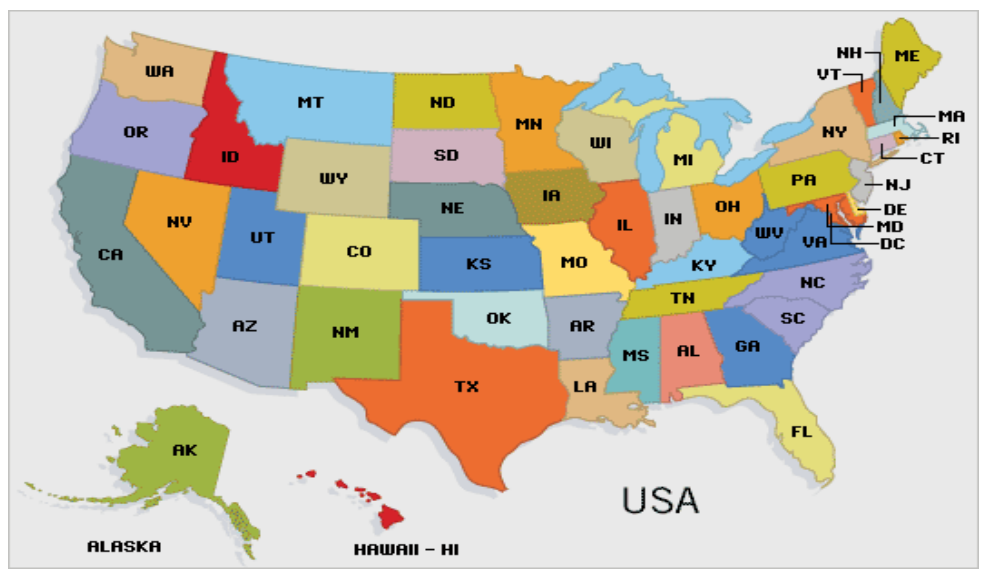

Figure 1: Map of the USA.

\footnotetext{
${ }^{5}$ For an illustration, see Dua and Ray (1995).
} 
have been made to alter this fact. Some studies have suggested relying more on the results from the loose versions of the prior (Dua and Ray (1995) and LeSage (1999)). Alternatively, LeSage and Pan (1995) have suggested the construction of the weight matrix based on the First-Order Spatial Contiguity (FOSC), which simply implies the creation of a non-symmetric $F$ matrix that emphasizes the importance of the variables from the neighboring states more than that of the non-neighboring states. Lesage and Pan (1995) suggests the use of a value of unity on not only the diagonal elements of the weight matrix, as in the Minnesota prior, but also in place(s) that correspond to the variable(s) from other state(s) with which the specific state in consideration have common border(s). However, for the elements in the $F$ matrix that corresponds to variable(s) from state(s) that are not immediate neighbor(s), Lesage and Pan (1995) proposes a value of 0.1 . Hence, eferring to the map of the US ${ }^{6}$, given in Figure 1, the design of the $F$ matrix based on the FOSC prior, given the alphabetical ordering ${ }^{7}$ of the twenty largest states, namely, AZ, CA, FL, GA, IL, IN, MA, MD, MI, MO, NC, NJ, NY, OH, PA, TN, TX, VA, WA and WI, can be formalized as follows:

$F=$\begin{tabular}{llllllllllllllllllll}
\hline 1.0 & 1.0 & 0.1 & 0.1 & 0.1 & 0.1 & 0.1 & 0.1 & 0.1 & 0.1 & 0.1 & 0.1 & 0.1 & 0.1 & 0.1 & 0.1 & 0.1 & 0.1 & 0.1 & 0.1 \\
1.0 & 1.0 & 0.1 & 0.1 & 0.1 & 0.1 & 0.1 & 0.1 & 0.1 & 0.1 & 0.1 & 0.1 & 0.1 & 0.1 & 0.1 & 0.1 & 0.1 & 0.1 & 0.1 & 0.1 \\
0.1 & 0.1 & 1.0 & 1.0 & 0.1 & 0.1 & 0.1 & 0.1 & 0.1 & 0.1 & 0.1 & 0.1 & 0.1 & 0.1 & 0.1 & 0.1 & 0.1 & 0.1 & 0.1 & 0.1 \\
0.1 & 0.1 & 1.0 & 1.0 & 0.1 & 0.1 & 0.1 & 0.1 & 0.1 & 0.1 & 0.1 & 0.1 & 0.1 & 0.1 & 0.1 & 0.1 & 0.1 & 0.1 & 0.1 & 0.1 \\
0.1 & 0.1 & 0.1 & 0.1 & 1.0 & 1.0 & 0.1 & 0.1 & 1.0 & 1.0 & 0.1 & 0.1 & 0.1 & 0.1 & 0.1 & 0.1 & 0.1 & 0.1 & 0.1 & 1.0 \\
0.1 & 0.1 & 0.1 & 0.1 & 1.0 & 1.0 & 0.1 & 0.1 & 1.0 & 0.1 & 0.1 & 0.1 & 0.1 & 1.0 & 0.1 & 0.1 & 0.1 & 0.1 & 0.1 & 0.1 \\
0.1 & 0.1 & 0.1 & 0.1 & 0.1 & 0.1 & 1.0 & 0.1 & 0.1 & 0.1 & 0.1 & 0.1 & 1.0 & 0.1 & 0.1 & 0.1 & 0.1 & 0.1 & 0.1 & 0.1 \\
0.1 & 0.1 & 0.1 & 0.1 & 0.1 & 0.1 & 1.0 & 1.0 & 0.1 & 0.1 & 0.1 & 0.1 & 0.1 & 0.1 & 1.0 & 0.1 & 0.1 & 1.0 & 0.1 & 0.1 \\
0.1 & 0.1 & 0.1 & 0.1 & 1.0 & 1.0 & 0.1 & 0.1 & 1.0 & 0.1 & 0.1 & 0.1 & 0.1 & 1.0 & 0.1 & 0.1 & 0.1 & 0.1 & 0.1 & 1.0 \\
0.1 & 0.1 & 0.1 & 0.1 & 1.0 & 0.1 & 0.1 & 0.1 & 0.1 & 1.0 & 0.1 & 0.1 & 0.1 & 0.1 & 0.1 & 0.1 & 0.1 & 0.1 & 0.1 & 0.1 \\
0.1 & 0.1 & 0.1 & 0.1 & 0.1 & 0.1 & 0.1 & 0.1 & 0.1 & 0.1 & 1.0 & 0.1 & 0.1 & 0.1 & 0.1 & 1.0 & 0.1 & 1.0 & 0.1 & 0.1 \\
0.1 & 0.1 & 0.1 & 0.1 & 0.1 & 0.1 & 0.1 & 0.1 & 0.1 & 0.1 & 0.1 & 1.0 & 1.0 & 0.1 & 1.0 & 0.1 & 0.1 & 0.1 & 0.1 & 0.1 \\
0.1 & 0.1 & 0.1 & 0.1 & 0.1 & 0.1 & 1.0 & 0.1 & 0.1 & 0.1 & 0.1 & 1.0 & 1.0 & 0.1 & 1.0 & 0.1 & 0.1 & 0.1 & 0.1 & 0.1 \\
0.1 & 0.1 & 0.1 & 0.1 & 0.1 & 1.0 & 0.1 & 0.1 & 1.0 & 0.1 & 0.1 & 0.1 & 0.1 & 1.0 & 1.0 & 0.1 & 0.1 & 0.1 & 0.1 & 0.1 \\
0.1 & 0.1 & 0.1 & 0.1 & 0.1 & 0.1 & 0.1 & 1.0 & 0.1 & 0.1 & 0.1 & 1.0 & 1.0 & 1.0 & 1.0 & 0.1 & 0.1 & 0.1 & 0.1 & 0.1 \\
0.1 & 0.1 & 0.1 & 0.1 & 0.1 & 0.1 & 0.1 & 0.1 & 0.1 & 1.0 & 1.0 & 0.1 & 0.1 & 0.1 & 0.1 & 1.0 & 0.1 & 0.1 & 0.1 & 0.1 \\
0.1 & 0.1 & 0.1 & 0.1 & 0.1 & 0.1 & 0.1 & 0.1 & 0.1 & 0.1 & 0.1 & 0.1 & 0.1 & 0.1 & 0.1 & 0.1 & 1.0 & 0.1 & 0.1 & 0.1 \\
0.1 & 0.1 & 0.1 & 0.1 & 0.1 & 0.1 & 0.1 & 1.0 & 0.1 & 0.1 & 1.0 & 0.1 & 0.1 & 0.1 & 0.1 & 0.1 & 0.1 & 1.0 & 0.1 & 0.1 \\
0.1 & 0.1 & 0.1 & 0.1 & 0.1 & 0.1 & 0.1 & 0.1 & 0.1 & 0.1 & 0.1 & 0.1 & 0.1 & 0.1 & 0.1 & 0.1 & 0.1 & 0.1 & 1.0 & 0.1 \\
0.1 & 0.1 & 0.1 & 0.1 & 1.0 & 0.1 & 0.1 & 0.1 & 1.0 & 0.1 & 0.1 & 0.1 & 0.1 & 0.1 & 0.1 & 0.1 & 0.1 & 0.1 & 0.1 & 1.0 \\
\hline & & & & & & & & & & & & & & & & & & & 0.1
\end{tabular}

The intuition behind this asymmetric $F$ matrix is based on our lack of belief on the prior means of zero imposed on the coefficient(s) for price(s) of the neighboring state(s). Instead we believe that these variables do have an important role to play, hence, to express our lack of faith in the prior means of zero, we assign a larger prior variance, by increasing the weight values, to these prior means on the coefficients for the variables of the neighboring states. This, in turn, allows the coefficients on these variables to be determined based more on the sample and less on the prior.

The BVARs and the SBVAR, based on the FOSC prior, are estimated using Theil's (1971) mixed estimation technique. Specifically, suppose we denote a single equation of the VAR model as: $y_{1}=X \beta+\varepsilon_{1}$, with $\operatorname{Var}\left(\varepsilon_{1}\right)=\sigma^{2} I$, then the stochastic prior restrictions for this single equation can be written as:

\footnotetext{
${ }^{6}$ The source for the US map is: http://www.submittheoffer.com/images/usa.gif.

${ }^{7}$ It must, however, be pointed out that alternative ordering of the twent largest US states do not affect our final results in any way.
} 


$$
\left[\begin{array}{c}
M_{111} \\
M_{112} \\
\cdot \\
\cdot \\
\cdot \\
M_{n n m}
\end{array}\right]=\left[\begin{array}{cccccc}
\sigma / \sigma_{111} & 0 & \cdot & \cdot & \cdot & 0 \\
0 & \sigma / \sigma_{112} & 0 & \cdot & \cdot & 0 \\
\cdot & \cdot & \cdot & \cdot & \cdot & \cdot \\
\cdot & \cdot & \cdot & \cdot & \cdot & \cdot \\
0 & \cdot & \cdot & \cdot & \cdot & 0 \\
0 & 0 & \cdot & \cdot & 0 & \sigma / \sigma_{n n m}
\end{array}\right]\left[\begin{array}{c}
a_{111} \\
a_{112} \\
\cdot \\
\cdot \\
\cdot \\
a_{n n m}
\end{array}\right]+\left[\begin{array}{c}
u_{111} \\
u_{112} \\
\cdot \\
\cdot \\
\cdot \\
u_{n n m}
\end{array}\right]
$$

Note, $\operatorname{Var}(u)=\sigma^{2} I$ and the prior means $M_{i j m}$ and $\sigma_{i j m}$ take the forms shown above for the Minnesota prior and for the FOSC prior. With (4) written as:

$$
r=R \beta+u
$$

and the estimates for a typical equation are derived as follows:

$$
\hat{\beta}=\left(X^{\prime} X+R^{\prime} R\right)^{-1}\left(X^{\prime} y_{1}+R^{\prime} r\right)
$$

Essentially then, the method involves supplementing the data with prior information on the distribution of the coefficients. The number of observations and degrees of freedom are increased by one in an artificial way, for each restriction imposed on the parameter estimates. The loss of degrees of freedom due to over- parameterization associated with a classical VAR model is therefore, not a concern in the BVARs and SBVAR.

\section{VARs, BVARs AND SBVAR MODELS FOR FORECASTING HOUSE PRICES IN TWENTY LARGEST US STATES}

Given the specification of the priors in Section 2, we estimate BVARs and a SBVAR model based on the FOSC prior for real house price growth of the twenty largest US states over the period of 1976:01 to 1994:04, using quarterly data. Then we compute the out-of-sample one- through four-quarters-ahead forecasts for the period of 1995:01 to 2006:04, and compare the forecast accuracy relative to that of the forecasts generated by an unrestricted VAR and the univariate versions of the VAR, or alternatively, autoregressive (AR) models, and the BVARs (for the same set of priors). The choice of the 48 quarters out-of-sample horizon is motivated by the fact that marked differences were observed in housing price growth across U.S. regions since the mid-1990s (Rapach and Staruss $(2007,2008)$ ). Once, we obtain the "optimal" model, i.e., the specific model for a particular state that produces, on average, the lowest Root Mean Squared Errors (RMSEs) over the period of 1995:01 to 2006:04, we use it to forecast ex ante and check whether the model in consideration could have predicted the downturn in the real house price growth over the period of 2007:01 to 2008:01. ${ }^{8}$ As pointed out above, the variables included in the models are the real house price growth of the twenty largest US States. The U.S. state-level nominal housing price data, obtained from the Freddie Mac, consists of quarterly observations from 1975:1 to 2006:4. Using matched transactions on the same property over time to account for quality changes, the Conventional Mortgage Home Price Index (CMHPI) of the Freddie Mac provides a means for measuring the typical price inflation for houses within the U.S. The data used by Freddie Mac consists of both purchase and refinance-appraisal transactions, and consists of over 33 million homes. A real housing price series is obtained by dividing the state-level CMHPI by the personal consumption expenditure (PCE) deflator obtained from the Bureau of Economic Analysis (BEA). All data are in their seasonally adjusted form in order to, inter alia, address the fact that, as pointed out by Hamilton (1994:362), the Minnesota-type priors are not well suited for seasonal data. Ultimately, we compute the annualized growth rates for the real house prices by multiplying 400 to the differences in the natural logs of the same.

In each equation of the VARs, classical or Bayesian, spatial or non-spatial (univariate or multivariate), there are 41 parameters including the constant, given the fact that the model is estimated with $2 \operatorname{lags}^{9}$ of each variable. Note Sims et al. (1990) indicates that with the Bayesian approach entirely based on the

\footnotetext{
${ }^{8}$ Based on our calculations of the real house price growth, we found all the 20 states under consideration to witness a decline in the real house price growth from 2007:01 onwards.

${ }^{9}$ The choice of 2 lags is based on the unanimity of the sequential modified LR test statistic, Akaike information criterion (AIC), the final prediction error (FPE) criterion, and the Hannan-Quinn (HQ) criterion.
} 
likelihood function, the associated inference does not need to take special account of nonstationarity, since the likelihood function has the same Gaussian shape regardless of the presence of nonstationarity. Given this, we do not formally report the tests of stationarity. ${ }^{10}$

The twenty-variable alternative BVAR models are estimated for an initial prior for the period of 1976:01 to 1994:04 and then, we forecast from 1995:01 through to 1995:04. Since we use two lags, the initial two quarters of the sample, 1976:01 to 1976:02, are used to feed the lags. We generate dynamic forecasts, as would naturally be achieved in actual forecasting practice. The models are re-estimated each quarter over the out-of-sample forecast horizon in order to update the estimate of the coefficients, before producing the 4-quarters-ahead forecasts. This iterative estimation and 4-steps-ahead forecast procedure was carried out for 48 quarters, with the first forecast beginning in 1995:01. This experiment produced a total of 48 one-quarter-ahead forecasts, 48-two-quarters-ahead forecasts, and so on, up to 48 4-step-ahead forecasts. We use the Kalman filter algorithm in RATS $^{11}$, for this purpose. The RMSEs $^{12}$ for the 48 , quarter 1 through quarter 4 forecasts are then calculated for the twenty real house price growth rates of the models. The average of the RMSE statistic values for one- to four-quartersahead forecasts for the period 1995:01 to 2006:04 are then examined. Identical steps are followed to generate the forecasts from the univariate and the multivariate forms of the VAR models, besides the BVARs, spatial and non-spatial (univariate and multivariate) for alternative values of the hyperparameters defining the priors. The model that produces the lowest average RMSE values is selected as the 'optimal' model for a specific state, and is then used to generate exante forecasts over the period of 2007:01 to 2008:01 to check whether that specific model could have predicted the recent downturn in real house price growth for a particular state.

\section{EVALUATION OF FORECAST ACCURACY}

In this section, we evaluate the accuracy of forecasts generated by the BVAR models, both spatial and non-spatial (univariate and multivariate), by comparing the RMSEs from the out-of-sample forecasts of these models with the same set of statistics generated from an unrestricted-multivariate classical VAR and the univariate VARs. In Table 1, we compare the average RMSEs of one- to four-quarters-ahead out-of-sample-forecasts for the period of 1995:01 to 2006:04, generated by the univariate VAR, the VAR, five alternative univariate BVARs, five alternative multivariate BVARs, and the SBVAR based on the FOSC prior. At this stage, a few words need to be said regarding the choice of the evaluation criterion for the out-of-sample forecasts generated from Bayesian models. As Zellner (1986: 494) points out the "optimal" Bayesian forecasts will differ depending upon the loss function employed and the form of predictive probability density function. In other words, Bayesian forecasts are sensitive to the choice of the measure used to evaluate the out-of-sample forecast errors. However, Zellner (1986) points out that the use of the mean of the predictive probability density function for a series, is optimal relative to a squared error loss function and the Mean Squared Error (MSE), and, hence, the RMSE is an appropriate measure to evaluate performance of forecasts, when the mean of the predictive probability density function is used. This is exactly what we do in Table 1, when we use the average RMSEs over the one- to four-quarter-ahead forecasting horizon. The conclusions from Table 1 can be summarized as follows:

\section{[INSERT TABLE 1]}

There does not exist an unique "optimal” model that performs the best in terms of lowest average RMSE for all the twenty states. Similar results were also obtained by Gupta and Das (2008) and Das et al. (2008) while analyzing the South African housing market; However, except for MA, in 19 of the 20 states, where the univariate VAR or the AR(2)

\footnotetext{
${ }^{10}$ However, using the Augmented Dickey-Fuller (ADF), the Phillips-Perron (PP), Dickey-Fuller-Genaralized Least Squares (DF-GLS), and the Kwiatkowski-Phillips-Schmidt-Shin (KPSS) tests, all the twenty real house price growth rates were found to be integrated of order 1, i.e., I(1).

${ }^{11}$ All statistical analysis was performed using WINRATS, version 7.0.

12 Note that if $A_{t+n}$ denotes the actual value of a specific variable in period $t+n$ and ${ }_{t} F_{t+n}$ is the forecast made in period $t$ for $t+n$, the RMSE statistic can be defined as $\sqrt{\frac{1}{N} \sum\left(A_{t+n}-{ }_{t} F_{t+n}\right)^{2}}$. For $n=1$, the summation runs from 1995:01 to 1995:04, and for $n=2$, the same covers the period of 1995:02 to 1996:01, and so on.
} 
model does the best, the BVARs, spatial or non-spatial (univariate or multivariate) outperforms the classical variants of the univariate and multivariate VARs;

Specifically, the univariate BVAR3 ( $w=0.1, d=1.0, k_{i j}=0.001$ ) outperforms all other models for IL, TN and WI, while, the univariate BVAR4 $(w=0.2, d=2.0)$ is "optimal” for AZ, TX and WA. The multivariate BVAR3 $\left(w=0.1, d=1.0, k_{i j}=0.5\right)$ does the best for NC and VA, with the multivariate BVAR1 ( $w=0.3, d=0.5, k_{i j}=0.5$ ) outperforming the alternative models for CA, FL, IN, MI, MO and OH, while the multivariate BVAR5 ( $\mathrm{w}=0.1, \mathrm{~d}=2.0, k_{i j}=0.5$ ) is the best-suited model for forecasting NJ. Finally, for GA, MD, NY and PA, the SBVAR model based on the FOSC prior is the standout performer; The athoeretical nature of the VARs make it quite difficult, if not impossible, to interpret the results, i.e., why is it the models perform in the way they do? However, given the basic structure of the VARs, univariate or multivariate, classical or Bayesian (spatial or non-spatial), we can make the following additional observations: (a) Generally, for the states, where the univariate VAR and the univariate BVARs do the best, it essentially implies that in those states, what matters most in determining the current real house price growth rate is the own lagged real house price growth rate. Moreover, given that it is generally the tight priored univariate BVARs that stand out amongst that specific class of models, is indicative of the fact that most of the variance in the current real house price growth rate comes from the first own lag of the same. In this regard, it is not surprising to see univariate BVAR4 doing the best for AZ, TX and WA - the states that do not share their borders with any of the other states in the country; (b) In addition, for states where the multivariate BVARs are the optimal models, the majority of them (6 out of 9 ) are the loose priored ones. This indicates that, lagged real house price growth rates of all the other states matter, besides the one in question plays a role in determining the current real house price growth rate, and; (c) Finally, for the states, where the SBVAR model stands out, namely, GA, MD, NY and PA, they are generally the ones with very prominent neighbors, as well as bordered by states, whose real house price growth rate, in turn, is determined mainly by itself, i.e., either by univariate BVARs or relatively tight priored multivariate BVARs.

In summary, what stands out though, is the fact that the BVARs, in whatever form they might be are the best performing models in majority of the cases, when compared to the classical variant of the univariate and multivariate VARs. Overall, the most loose priored multivariate BVAR does the best for 6 states, followed by the SBVAR for 4 cases. Two of the relatively tight priored univariate BVARs are the best performing models for 3 additional cases each, while the 3 of the remaining 4 cases are shared between the two relatively tight multivariate BVARs, with the univariate classical VAR standing out for just one state.

\section{PREDICTING THE TURNING POINTS}

This section is devoted to analyzing the capability of the "optimal" model in predicting the recent downturn in the real house price growth rate of the 20 largest US states over the ex ante forecast period of 2007:01 to 2008:01. ${ }^{13}$ As can be seen from the Figures 2 through 21, the optimal models does quite well for GA, IL, MO, NC, NY, OH, PA, TN, TX, VA, WA and WI, and only partially well for AZ, CA, FL, IN, MD and MI. Overall, except for NJ and MA, the "optimal" model corresponding to a specific state does reasonably well in tracking the downturn. Note the optimal model for MA was the univariate VAR, so the "optimal" Bayesian models are well-equipped in predicting the downturn in 18 of the 19 cases, with the exception of NJ. However, in all the cases, where the "optimal" models predicted the downturn correctly, the tended to under-predict the size of the decline in the real house price growth rate. This is not surprising, especially when one takes into account of the fact that though lagged values of house prices contains useful information, the recent downturn in the housing market has to do with the adverse effects on the fundamentals affecting the house prices. Nevertheless, the ability of the "optimal" models, majority of which are Bayesian in nature, in predicting the recent downturn cannot be disregarded. These models, as shown here, could be used efficiently (in the sense

\footnotetext{
${ }^{13}$ The period 2007:01 to 2008:01 is dubbed ex ante simply because our sample for the model ends at 2006:04. However, given the availability of data till 2008:01, we can compare the future forecasts from the model with the original data.
} 
that not too much information is required) to obtain a preliminary and prompt feel about where a specific variable might be headed, and, hence, as pointed out by Del Negro (1999), can be of immense importance to policy makers.

\title{
[INSERT FIGURES 2 THROUGH 21]
}

\author{
6. CONCLUSIONS
}

This paper estimates Bayesian Vector Autoregressive (BVAR) models, both spatial and non-spatial (univariate and multivariate), for twenty largest states of the US economy, using quarterly data over the period 1976:Q1 to 1994:Q4; and then forecasts one-to-four quarters ahead real house price growth over the 48 quarters out-of-sample forecast horizon of 1995:Q1 to 2006:Q4. The forecasts are then evaluated by comparing them with the ones generated from an unrestricted classical Vector Autoregressive (VAR) model and the corresponding univariate variant of the same. Finally, the models that produce the minimum average Root Mean Square Errors (RMSEs) are used to predict the downturns in the real house price growth over the recent period of 2007:Q1 to 2008:Q1.

In general, we draw the following conclusions: (a) The BVARs, in whatever form they might be, i.e., spatial or non-spatial (univariate or multivariate) are the best performing models in 19 of the 20 states, when compared to the classical variant of the univariate and multivariate VARs; (b) The "optimal" Bayesian models do a fair job in predicting the downturn in 18 of the 19 states for which they produced the minimum RMSEs on average; (c) However, the "optimal" models were always found to underpredict the size of the decline in the real house price growth rate, this, perhaps, being an indication of the importance of the adverse effects of fundamentals on real house prices, over and beyond the information contained in the past house prices. Given this, an immediate extension of this study would be to analyze how well the Autoregressive Distributed Lag (ARDL) models developed by Rapach and Strauss $(2007,2008)$ would compare in predicting the turning points in the data. Moreover, an alternative approach would be to develop a Dynamic Factor Model (DFM) as in Das et al. (2008) that would allow for the role of large number of potential predictors, or one might want to delve into designing a large-scale BVAR model, along the lines of Gupta and Kabundi (2008a), which would allow for not only the role of large number of fundamentals affecting the real house price growth but also for asymmetric interaction from national-, regional and state-level (neighbors or nonneighbors) variables, and; (d) Finally, overall, the ability of the atheoretical Bayesian models, as quick and preliminary predictors of real house price growth rate cannot be disregarded.

At this stage, it must be pointed out that there are at least two limitations to using a Bayesian approach for forecasting. Firstly, as it is clear from Table 1, the forecast accuracy is sensitive to the choice of the priors. So if the prior is not well specified, an alternative model used for forecasting may perform better. Secondly, in case of the Bayesian models, one requires to specify an objective function, for example the average RMSEs, to search for the 'optimal' priors, which, in turn, needs to be optimized over the period for which we compute the out-of-sample forecasts. However, there is no guarantee that the chosen parameter values specifying the prior will continue to be 'optimal' beyond the period for which it was selected. Nevertheless, the importance of the Bayesian forecasting models, spatial or nonspatial (univariate or multivariate), cannot be underestimated. This has been widely proven in the forecasting literature ${ }^{14}$, and is also vindicated by our current study, which indicates the suitability of the Bayesian models in forecasting and predicting the turning points in the real house price growth rates of 20 largest states of the US economy.

\section{REFERENCES}

Amirizadeh, H. and Todd, R. M. (1984). More Growth Ahead for Ninth District States. Quarterly Review, Federal Reserve Bank of Minneapolis, Fall.

Banerji, A., Dua, P. and Miller, S. M. (2006). Performance Evaluation of the New Connecticut Leading Employment Index Using Lead Profiles and BVAR Models. Journal of Forecasting, 25(6), 415-437.

Das, S., Gupta, R. and Kabundi, A. (2008). Is a DFM Well-Suited for Forecasting Regional House

\footnotetext{
${ }^{14}$ For example, Amirizadeh and Todd (1984), Kuprianov and Lupoletti (1984), Hoen et al. (1984), Hoen and Balazsy (1985), Kinal and Ratner (1986), Gruben and Long (1988a, b), LeSage (1990), Gruben and Hayes (1991), Shoesmith (1992, 1995), Dua and Ray (1995), Dua and Smyth (1995), Dua and Miller (1996), Dua et al. (1999), Gupta and Sichei (2006), Gupta (2006, 2007), Liu and Gupta (2007), Zita and Gupta (2007), Banerji et al (2008), Das et al. (2008), Gupta and Das (2008), Gupta and Kabundi (2008b) , and Liu et al. (2007, 2008).
} 
Price Inflation? Forthcoming Economic Research Southern Africa (ERSA) Working Paper.

Doan, T. A., Litterman, R. B. and Sims, C. A. (1984). Forecasting and Conditional Projections Using Realistic Prior Distributions. Econometric Reviews, 3(1), 1-100.

Dua, P. and Ray, S. C. (1995). A BVAR Model for the Connecticut Economy. Journal of Forecasting, 14(3), 167-180.

Dua, P. and Miller, S. M. (1996). Forecasting and Analyzing Economic Activity with Coincident and Leading Indexes: The Case of Connecticut. Journal of Forecasting, 15(7), 509-526.

Dua, P. and Smyth, D. J. (1995). Forecasting U. S. Home Sales using BVAR Models and Survey Data on Households’ Buying Attitude. Journal of Forecasting, 14(), 167-180.

Dua, P., Miller, S. M. and Smyth, D. J. (1999). Using Leading Indicators to Forecast U. S. Home Sales in a Bayesian Vector Autoregressive Framework. Journal of Real Estate Finance and Economics, 18(2), 191-205.

Gupta, R. and Sichei, M. M. (2006). A BVAR Model for the South African Economy. South African Journal of Economics, 74(3), 391-409.

Gupta, R. (2006). Forecasting the South African Economy with VARs and VECMs. South African Journal of Economics, 74(4), 611-628.

Gupta, R. (2007a). Bayesian Methods of Forecasting Inventory Investment in South Africa. Working Paper Department of Economics, University of Pretoria, No. 200724.

Gupta, R. (2007b). Forecasting the South African Economy with Gibbs Sampled BVECMs. South African Journal of Economics, 75(4), 631-643.

Gupta, R. and Das, S. (2008). Spatial Bayesian Methods for Forecasting House Prices in Six Metropolitan Areas of South Africa. Forthcoming South African Journal of Economics.

Gupta, R. and Kabundi, A (2008a). Forecasting Macroeconomic Variables using Large Datasets: Dynamic Factor Model vs Large-Scale BVARs. Working Paper, University of Pretoria, Department of Economics, No. 200816.

Gupta, R. and Kabundi, A. (2008b). A Dynamic Factor Model for Forecasting Macroeconomic Variables in South Africa. Working Paper, University of Pretoria, Department of Economics, No. 200815.

Gruben, W. C. and Hayes, D. W. (1991). Forecasting the Louisiana Economy. Economic Review, Federal Reserve Bank of Dallas, March, 1-16.

Gruben, W. C. and Long III, W. T. (1988a). Forecasting the Texas Economy: Application and Evaluation of a Systematic Multivariate Time-Series Model Outlook for 1989. Economic Review, Federal Reserve Bank of Dallas, January, 11-25.

Gruben, W. C. and Long III, W. T. (1988b). The New Mexico Economy: Outlook for 1989. Economic Review, Federal Reserve Bank of Dallas, November, 21-29.

Hamilton, J. D. (1994). Time Series Analysis. Second Edition. Princeton: Princeton University Press. Hoen, J. G., Gruben, W. C. and Fomby, T. B. (1984). Time Series Forecasting Model of Texas Economy: A Comparison. Economic Review, Federal Reserve Bank of Dallas, May, 11-23.

Hoen, J. G. and Balazsy, J. J. (1985). The Ohio Economy: A Time-Series Analysis. Economic Review, Federal Reserve Bank of Cleveland, Third Quarter, 25-36.

Kinal, T. and Ratner, J. (1986). A VAR Forecasting Model of a Regional Economy: Its Construction and Comparison. International Regional Science Review, 10(2), 113-126.

Kuprianov, A. and Lupoletti, W. (1984). The Economic Outlook for the Fifth District States in 1984: Forecasts from Vector Autoregression Models. Economic Review, Federal Reserve Bank of Richmond, February, 12-23.

LeSAGE, J. P. and Pan, Z. (1995). Using Spatial Contiguity as Bayesian Prior Information in Regional Forecasting Models, International Regional Science Review, 18(1), 33-53.

LeSAGE, J. P. (1999). Applied Econometrics Using MATLAB, www.spatial-econometrics.com.

Litterman, R. B. (1981). A Bayesian Procedure for Forecasting with Vector Autoregressions. Working Paper, Federal Reserve Bank of Minneapolis.

Litterman, R. B. (1986). Forecasting with Bayesian Vector Autoregressions - Five Years of Experience. Journal of Business and Economic Statistics, 4 (1), 25-38.

Liu, G. and Gupta, R. (2007). A Small-Scale DSGE Model for Forecasting the South African Economy. South African Journal of Economics, 75(2), 179-193.

Liu, G., Gupta, R. and Schaling, E. (2007b). Forecasting the South African Economy: A DSGE-VAR Approach. Working Paper Department of Economics, University of Pretoria, No. 200724

Liu, G., Gupta, R. and Schaling, E. (2008). A New Keynesian DSGE Model for Forecasting the South African Economy. Working Paper Department of Economics, University of Pretoria, No. 200805

NAR, National Association of Realtors. (2006) Existing-Home Sales Slip in April, (http://www.realtor.org/PublicAffairsWeb.nsf/Pages/EHS06April) Accessed on June 8, 2006. 
Rapach, D.E. and Strauss, J.K. (2007). Forecasting Real Housing Price Growth in the Eighth District States. Federal Reserve Bank of St. Louis. Regional Economic Development, 3(2), 33-42.

Rapach, D.E. and Strauss, J.K. (2008). Differences in Housing Price Forecast ability Across U.S. States. Mimeo, Department of Economics, St. Louis University.

Shoesmith, G. L. (1992). Co-integration, Error Correction and Medium-Term Regional VAR Forecasting. Journal of Forecasting, 11(1), 91-109.

Shoesmith, G. L. (1995). Multiple Cointegrating Vectors, Error Correction, and Litterman's Model. International Journal of Forecasting, 11(4), 557-567.

Sims, C. A. (1980). Macroeconomics and Reality. Econometrica, 48(1), 1-48.

Sims, C. A., Stock, J. H. and Watson, M. W. (1990). Inference in Linear Time Series Models with Some Unit Roots. Econometrica, 58(1), 113-144.

Spencer, D. E. (1993). Developing a Bayesian Vector Autoregression Model. International Journal of Forecasting, 9(3), 407-421.

Stock, J. H., and Watson, M.W. (2003). Forecasting Output and Inflation: The Role of Asset Prices. Journal of Economic Literature, 41(3), 788-829.

Theil, H. (1971). Principles of Econometrics. New York: John Wiley.

Todd, R. M. (1984). Improving Economic Forecasting with Bayesian Vector Autoregression. Quarterly Review, Federal Reserve Bank of Minneapolis, Fall, 18-29.

Zellner, A., (1986). A Tale of Forecasting 1001 Series: The Bayesian Knight Strikes Again. International Journal of Forecasting, 2(4), 494-494.

Zita, S. E. and Gupta, R. (2008). Modelling and Forecasting the Metical-Rand Exchange Rate. Working Paper, University of Pretoria, Department of Economics, No. 200702. 
Table1. One-to -Four- Quarters-Ahead Average RMSEs (2001:01-2006:04)

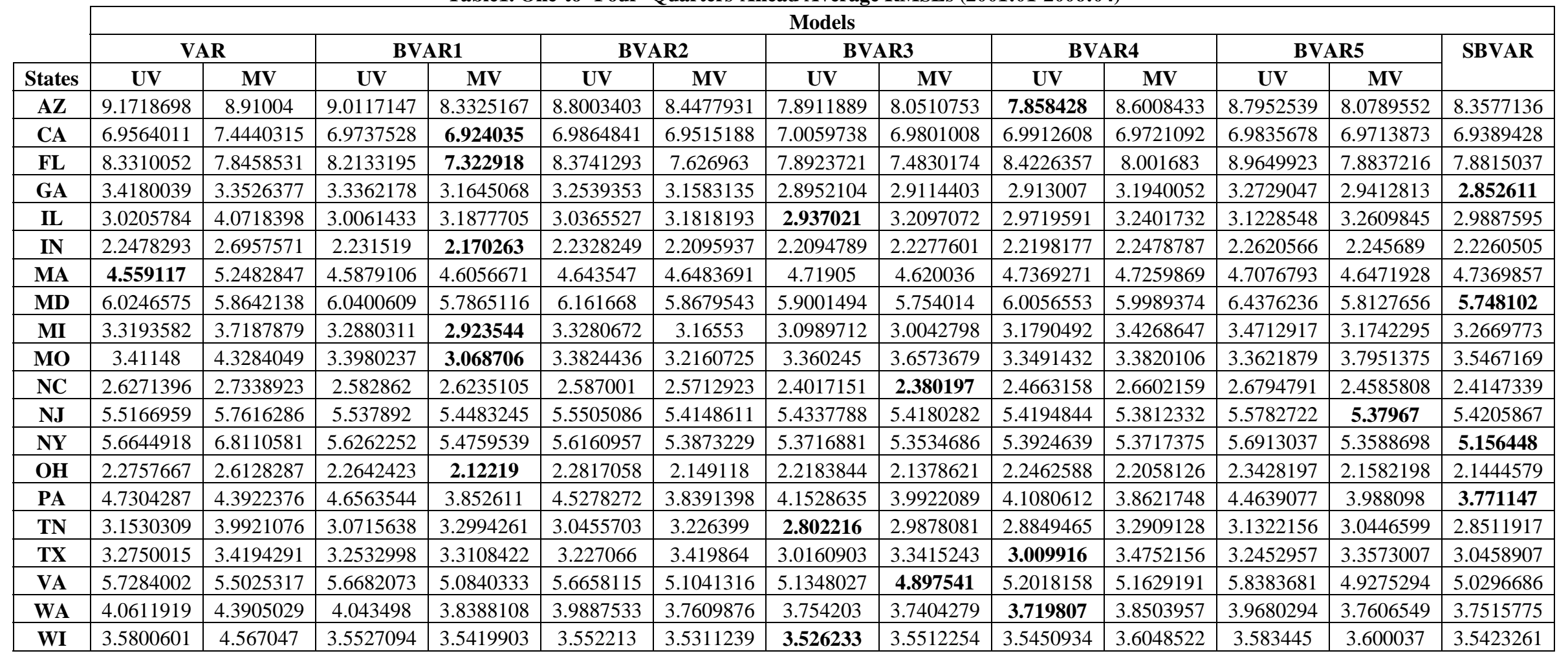

Notes: UV(Univariate); MV(Multivariate); BVAR1(w=0.3,d=0.5); BVAR2(w=0.2,d=1.0); BVAR3(w=0.1,d=1.0);BVAR4(w=0.2,d=2.0), BVAR5(w=0.1,d=2.0). 
Figure 2. Predicting Turning Points for AZ (2007:01-2008:01)

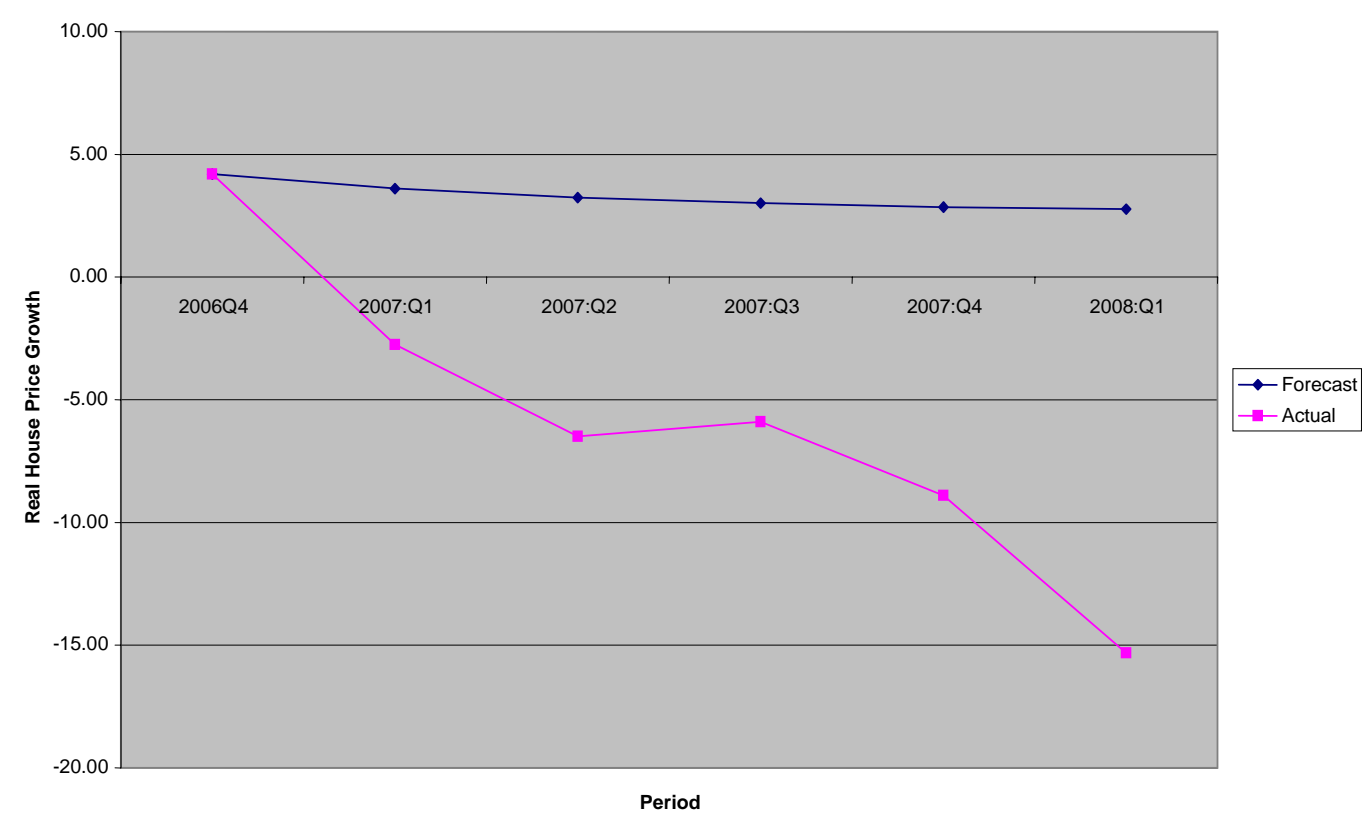

Figure 3. Predicting Turning Points for CA (2007:01-2008:01)

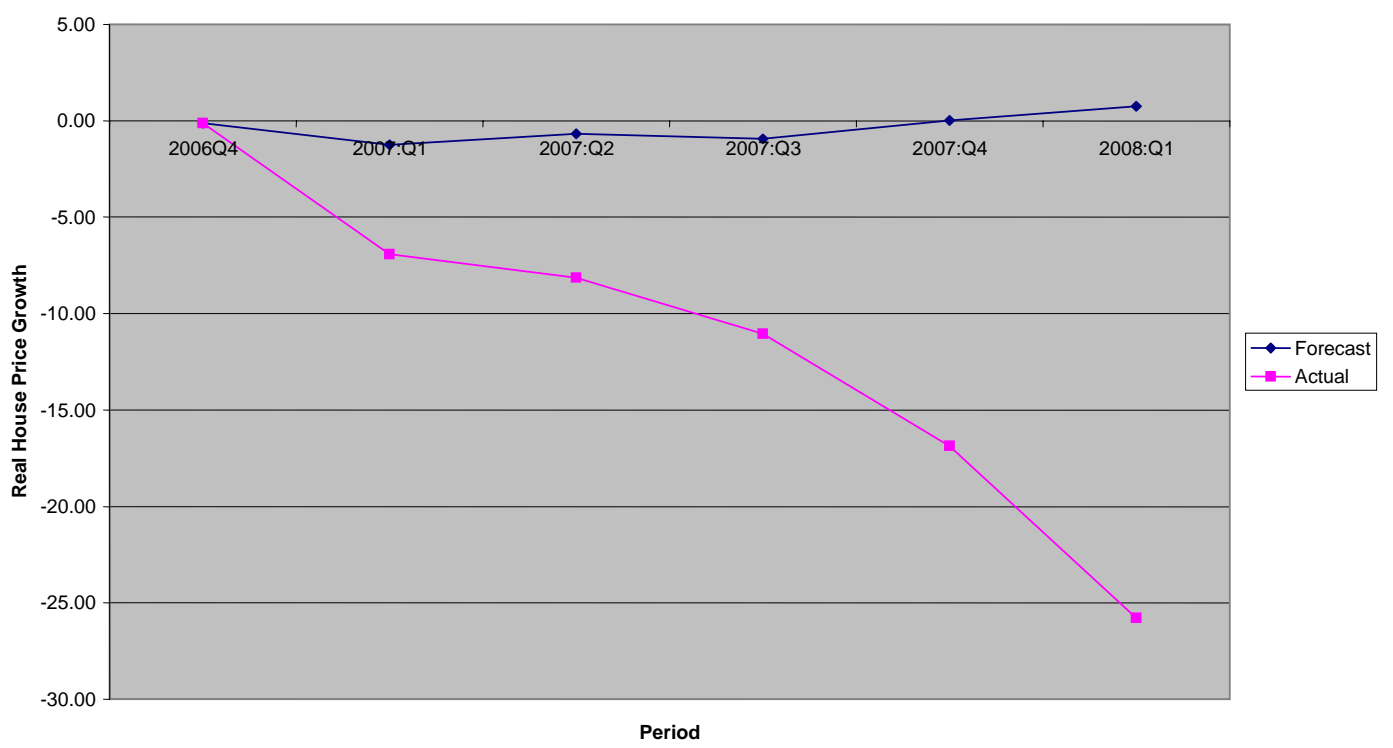


Figure 4. Predicting Turning Points for FL (2007:01-2008:01)

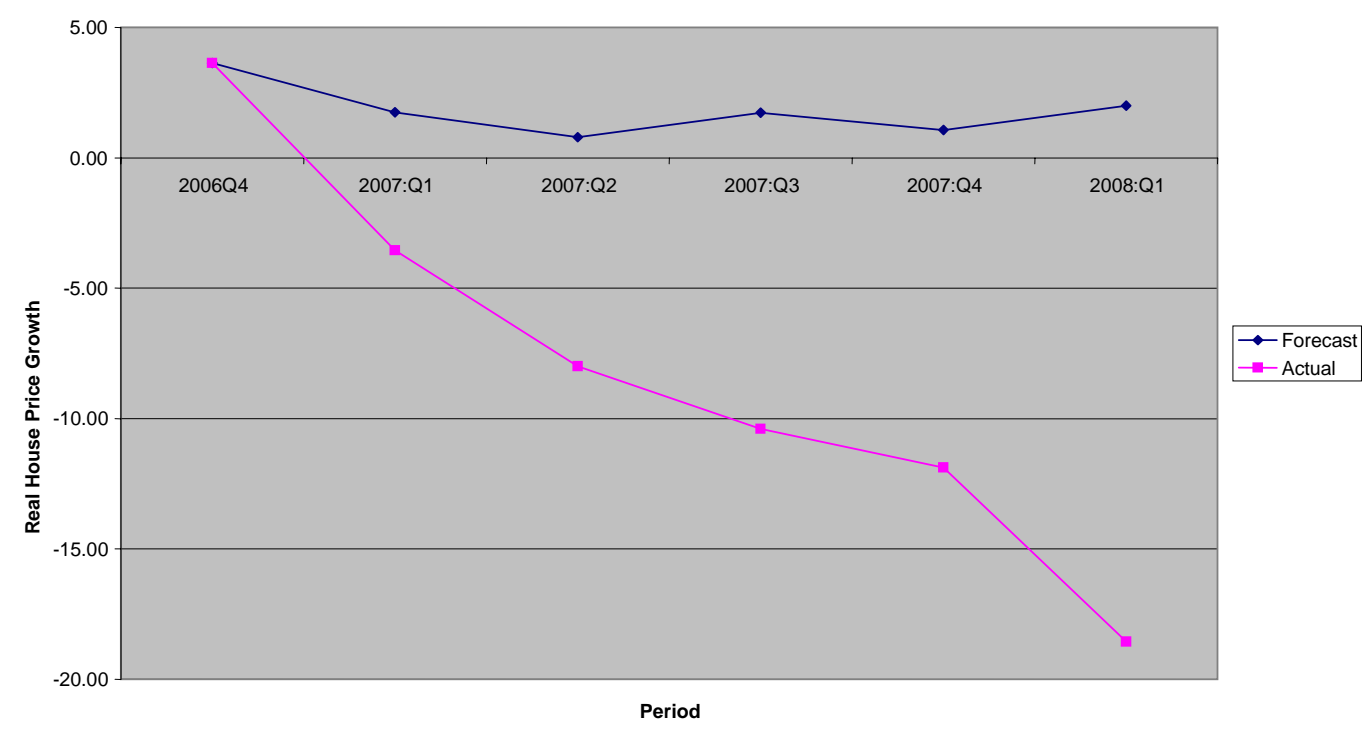

Figure 5. Predicting turning Points for GA ( 2007:01-2008:01)

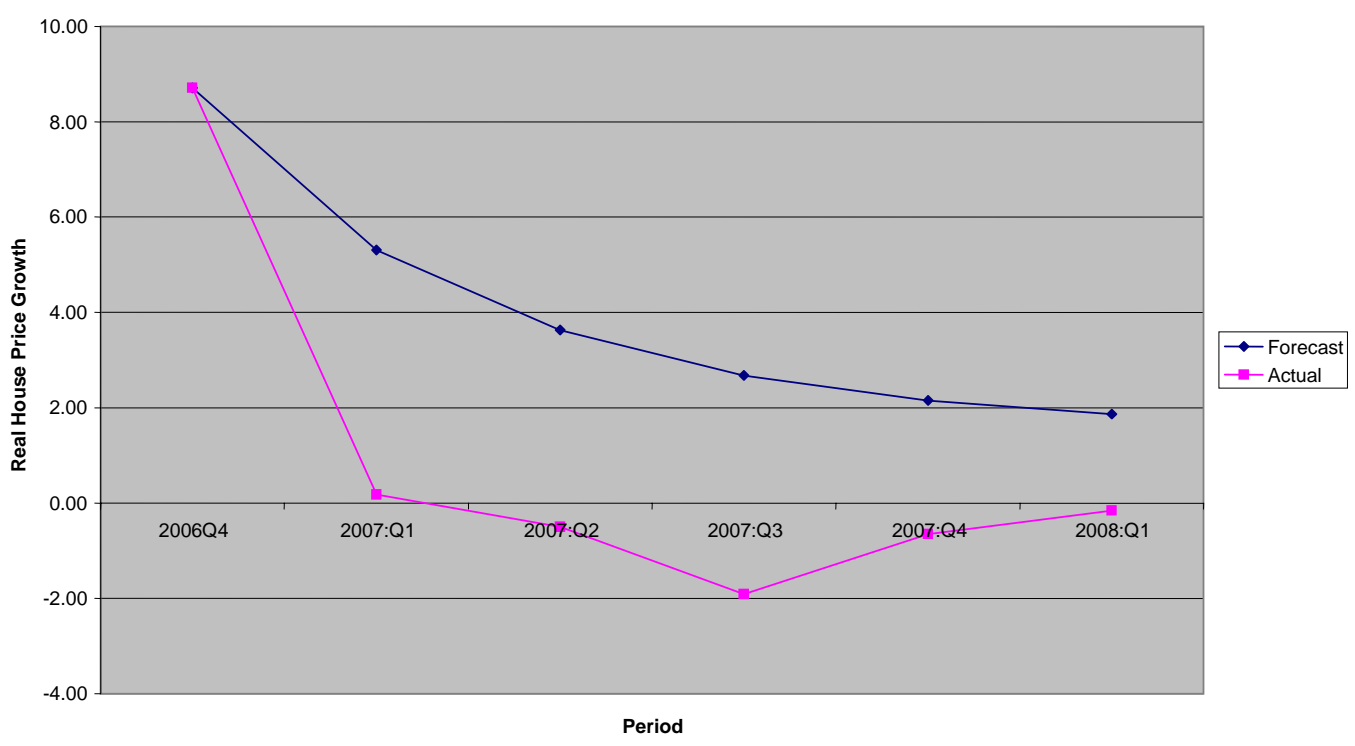


Figure 6. Predicting Turning Points for IL (2007:01-2008:01)

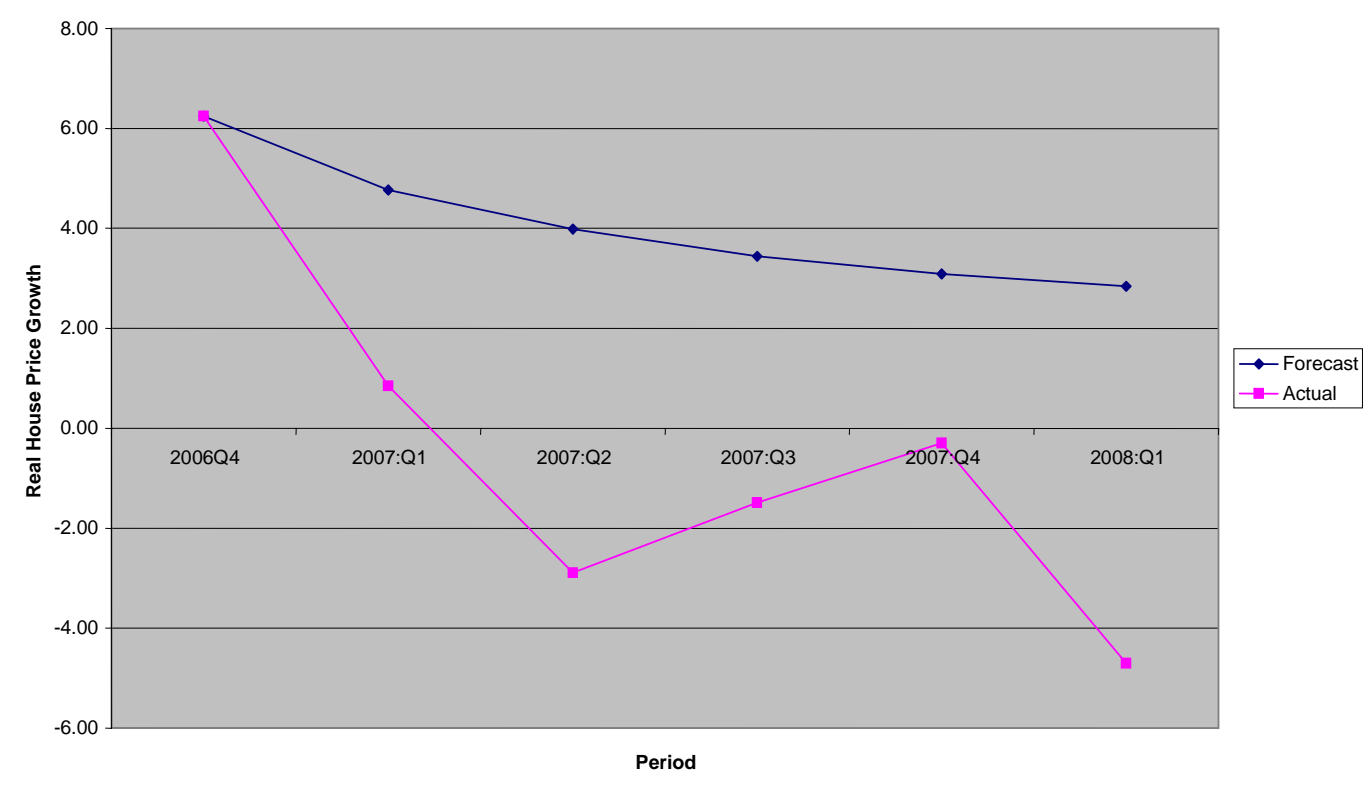

Figure 7. Predicting Turning Points for IN (2007:01-2008:01)

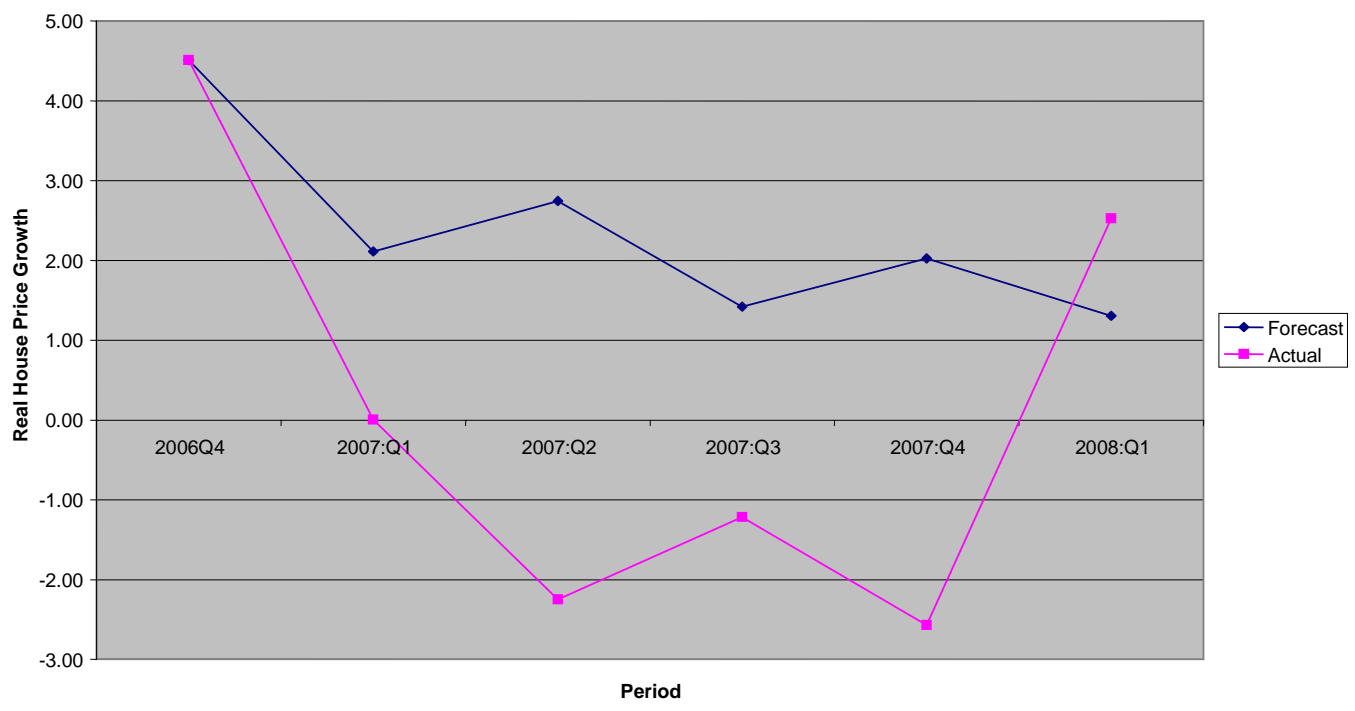


Figure 8. Predicting Turning Points for MA (2007:01-2008:01)

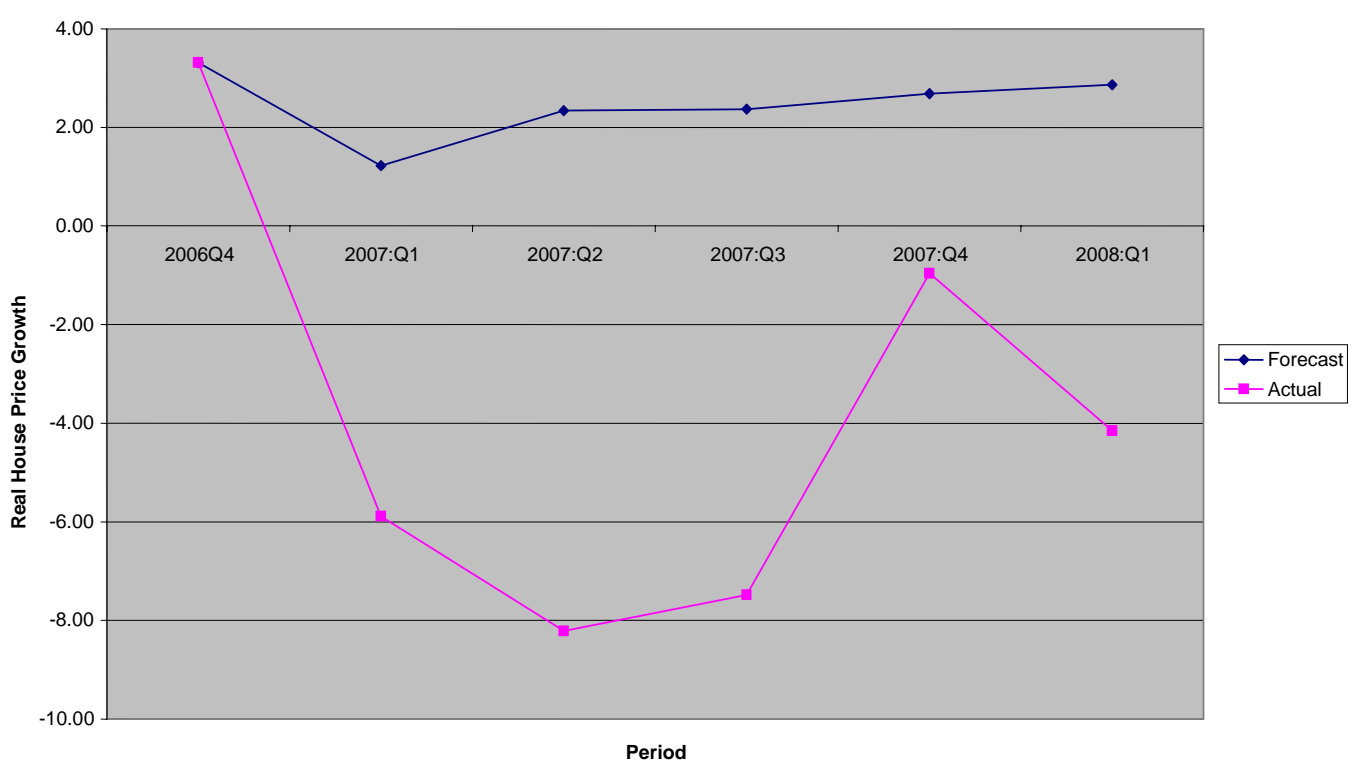

Figure 9. Predicting Turning Points for MD (2007:01-2008:01)

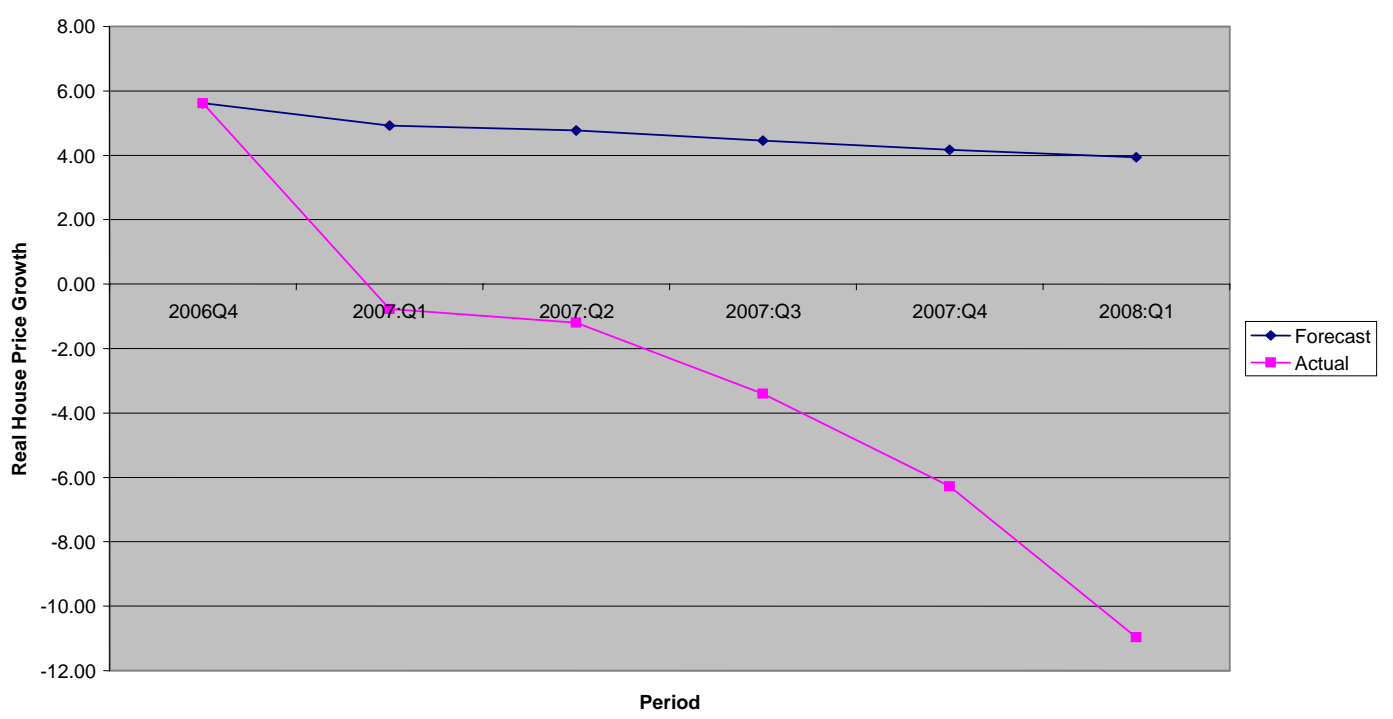


Figure 10. Predicting Turning Points for MI (2007:01-2008:01)

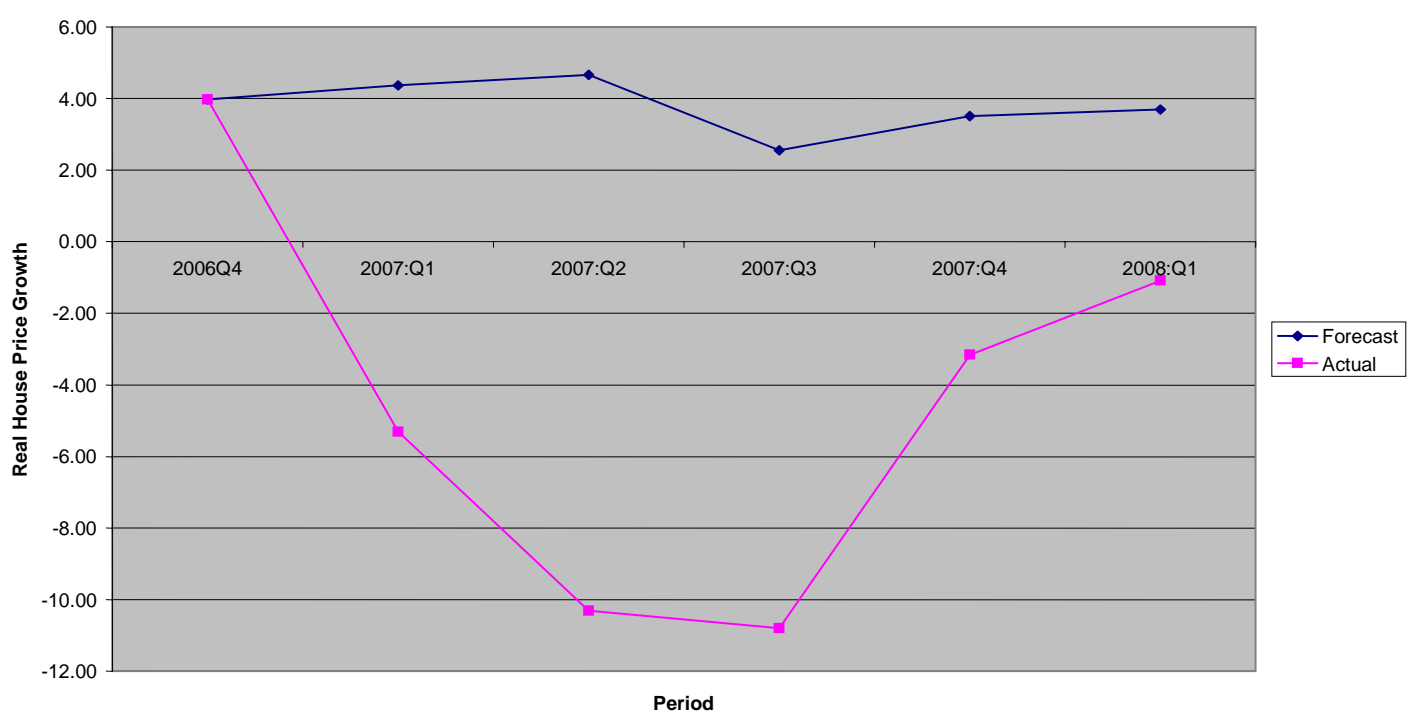

Figure 11. Predicting turning Points for MO (2007:01-2008:01)

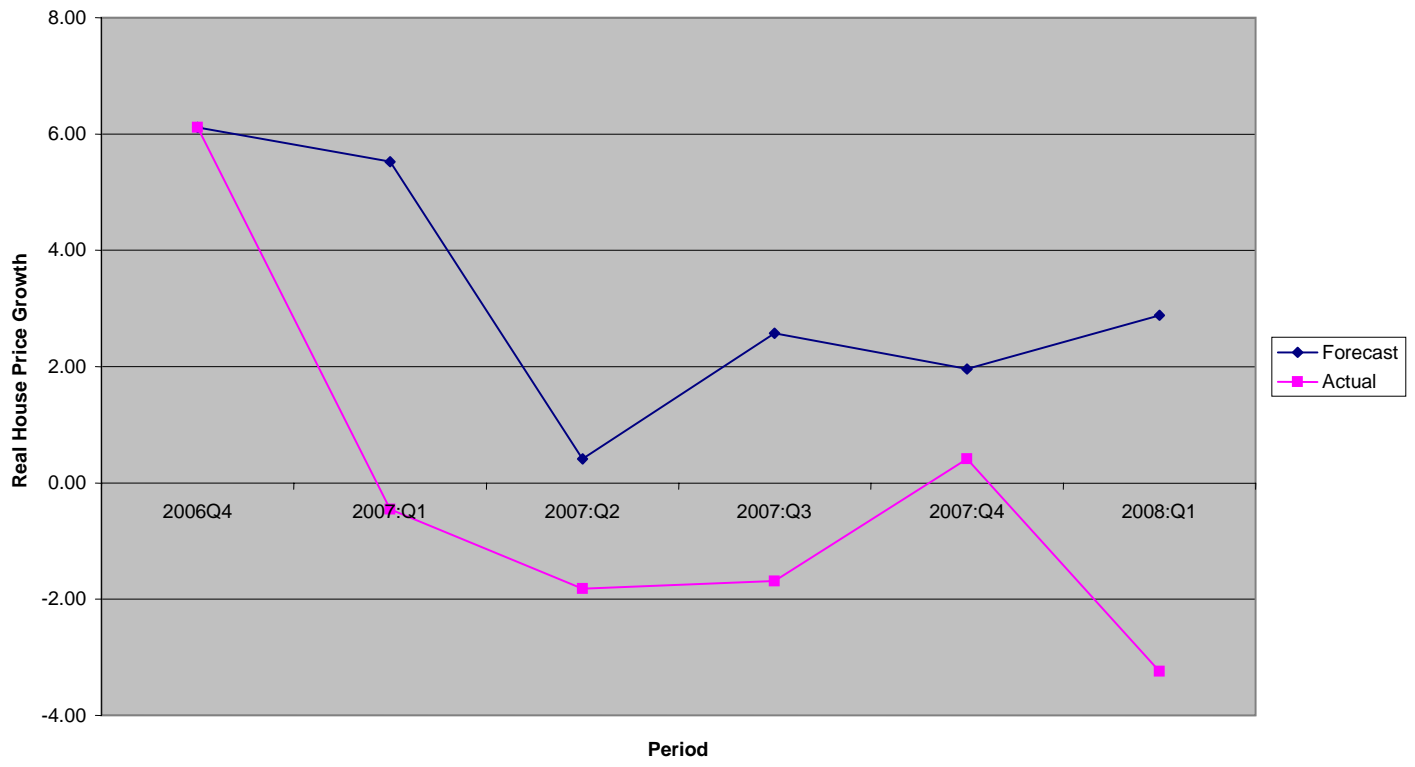


Figure 12. Predicting Turning Points for NC (2007:01-2008:01)

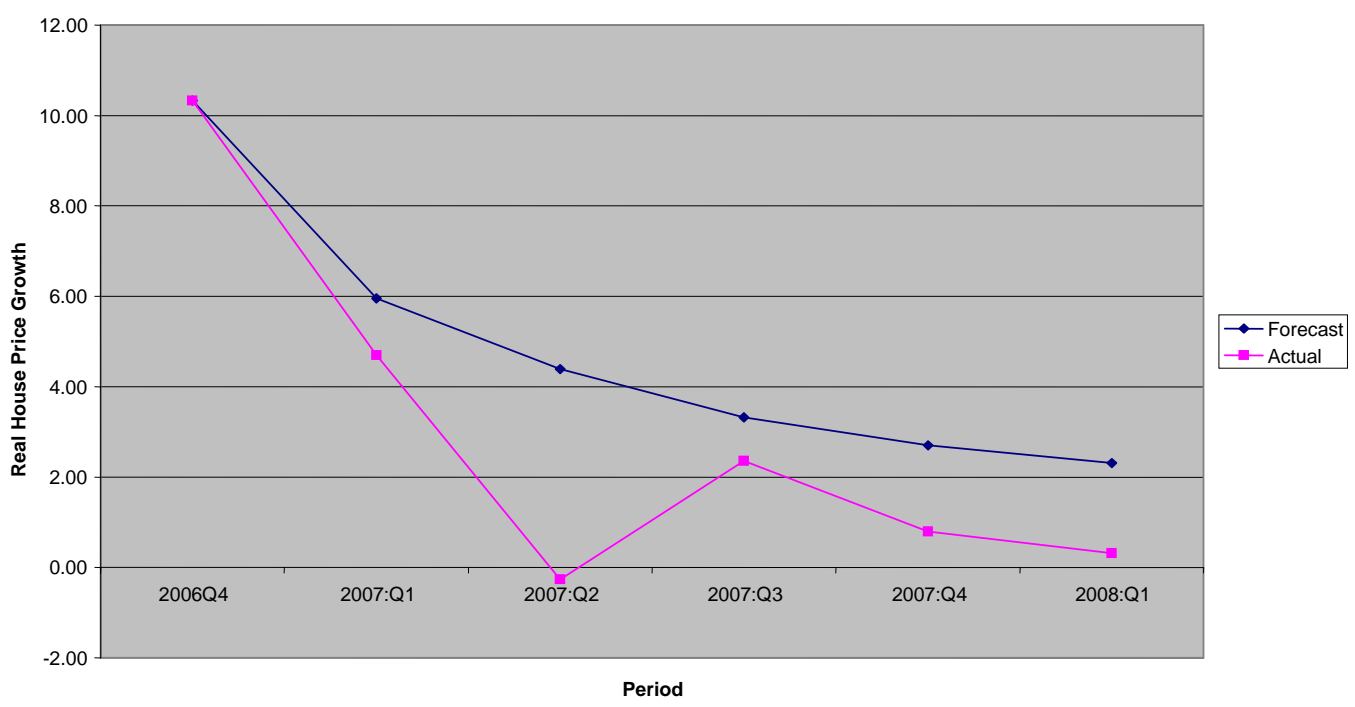

Figure 13. Predicting Turning Points for NJ (2007:01-2008:01)

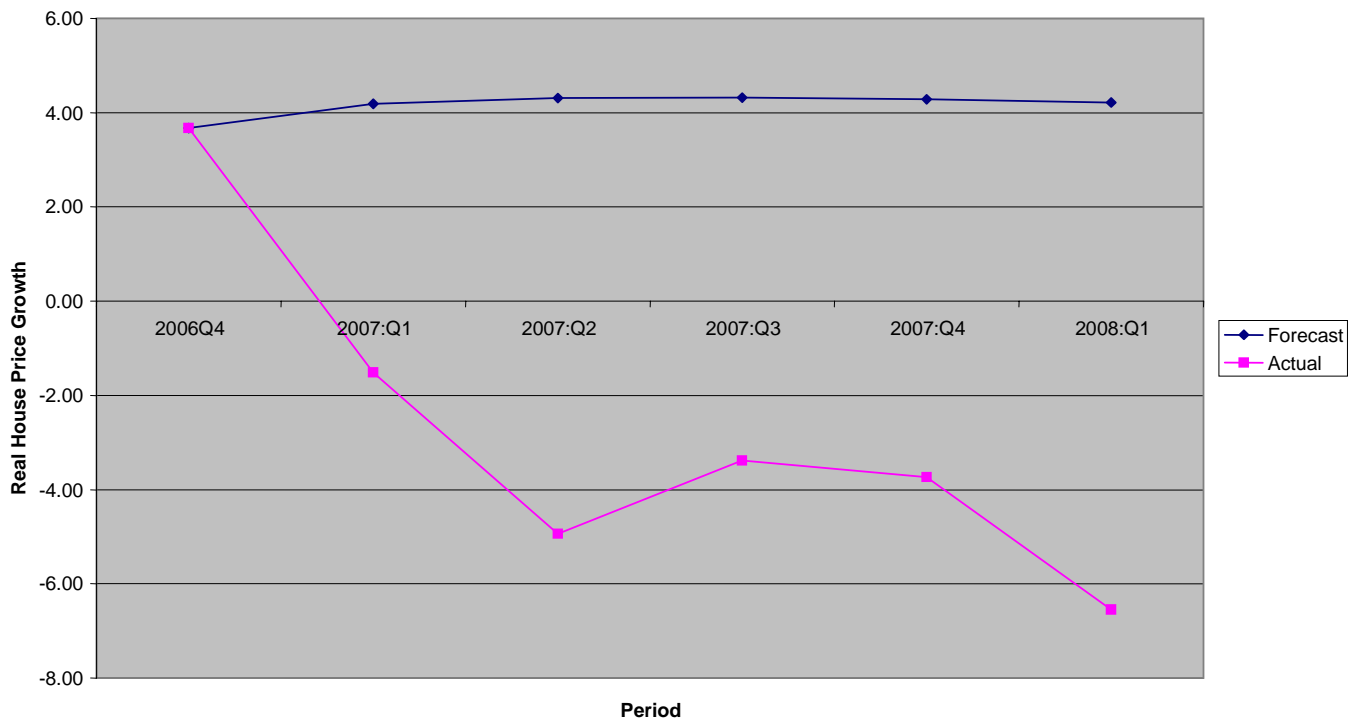


Figure 14. Predicting Turning Points for NY (2007:01-2008:01)

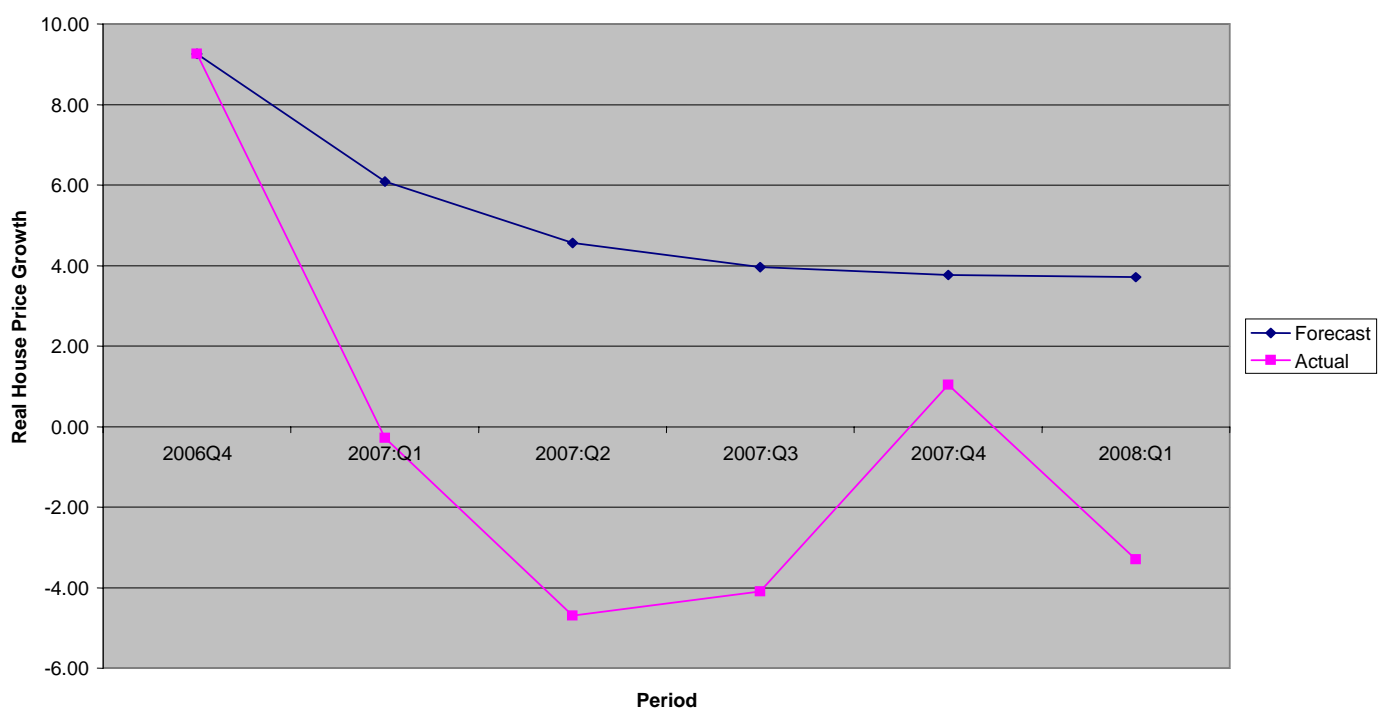

Figure 15. Predicting Turning Points for $\mathrm{OH}$ (2007:01-2008:01)

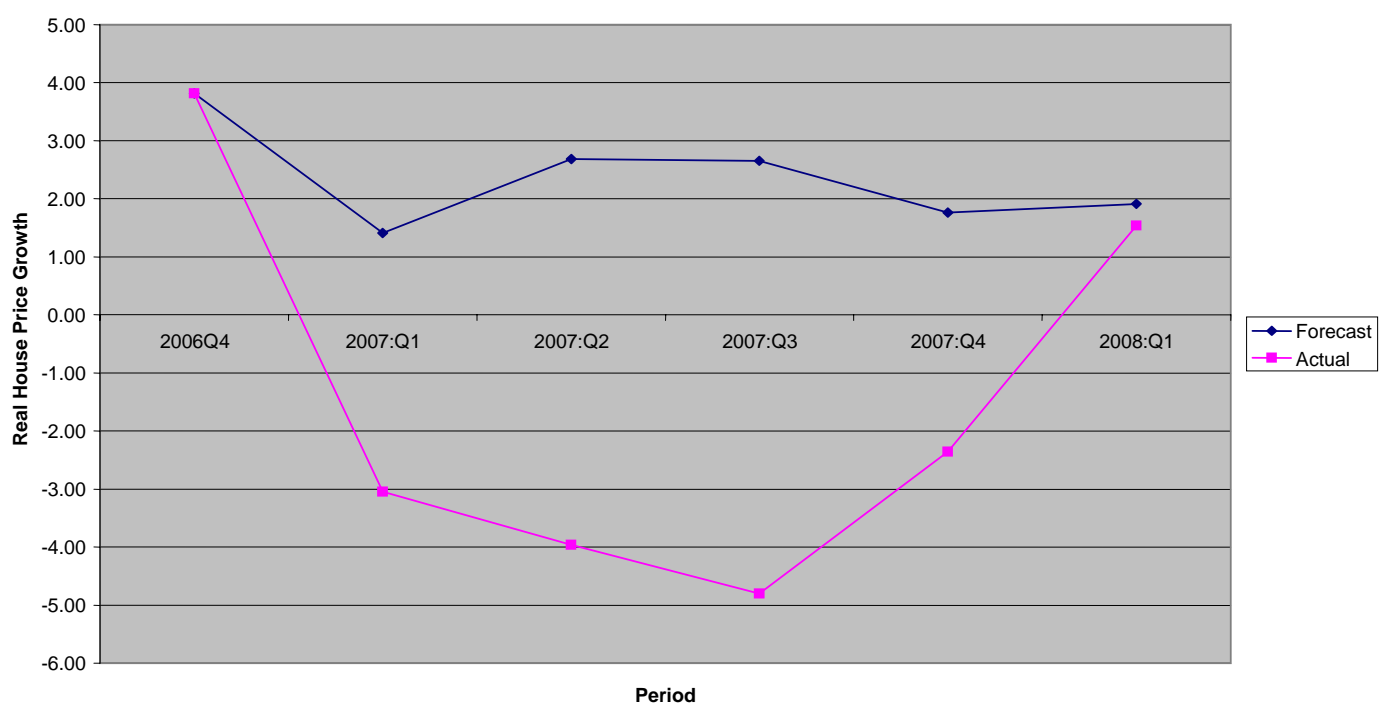


Figure 16. Predicting Turning Points for PA (2007:01-2008:01)

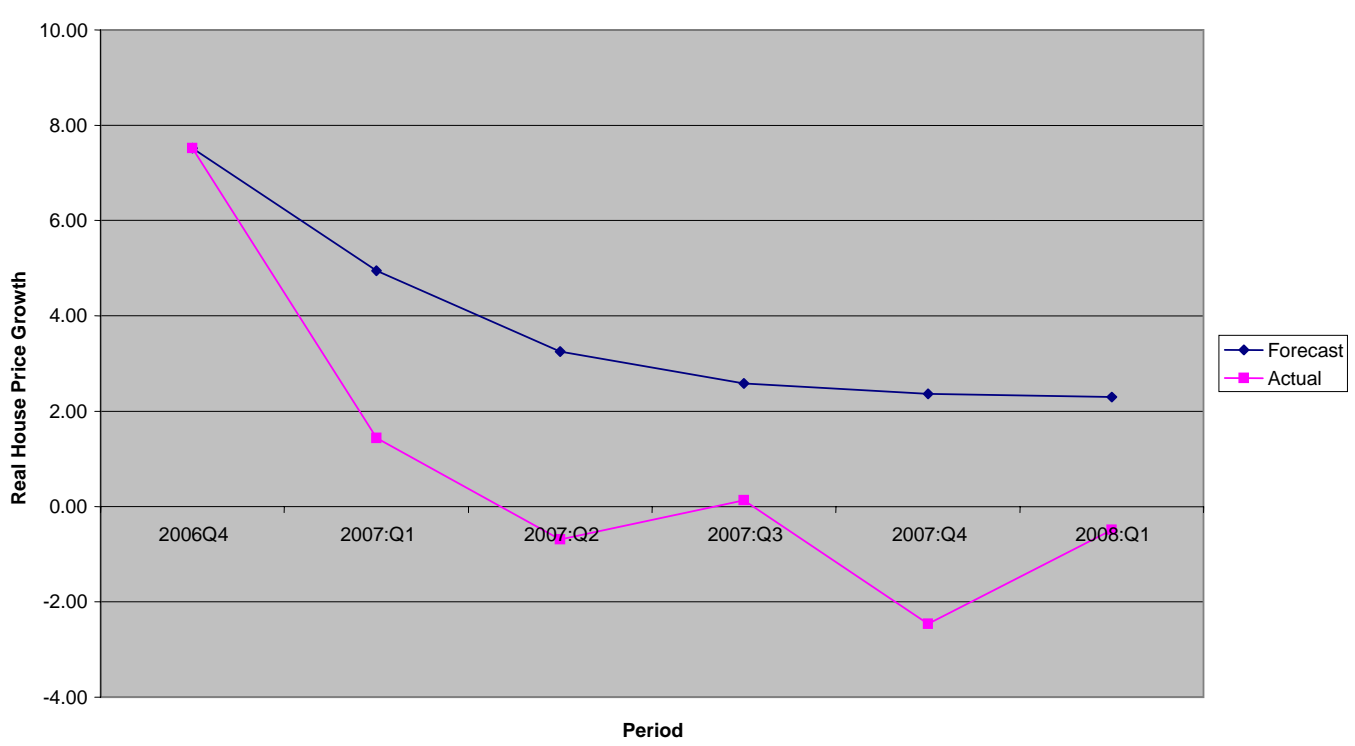

Figure 17. Predicting Turning Points for TN (2007:01-2008:01)

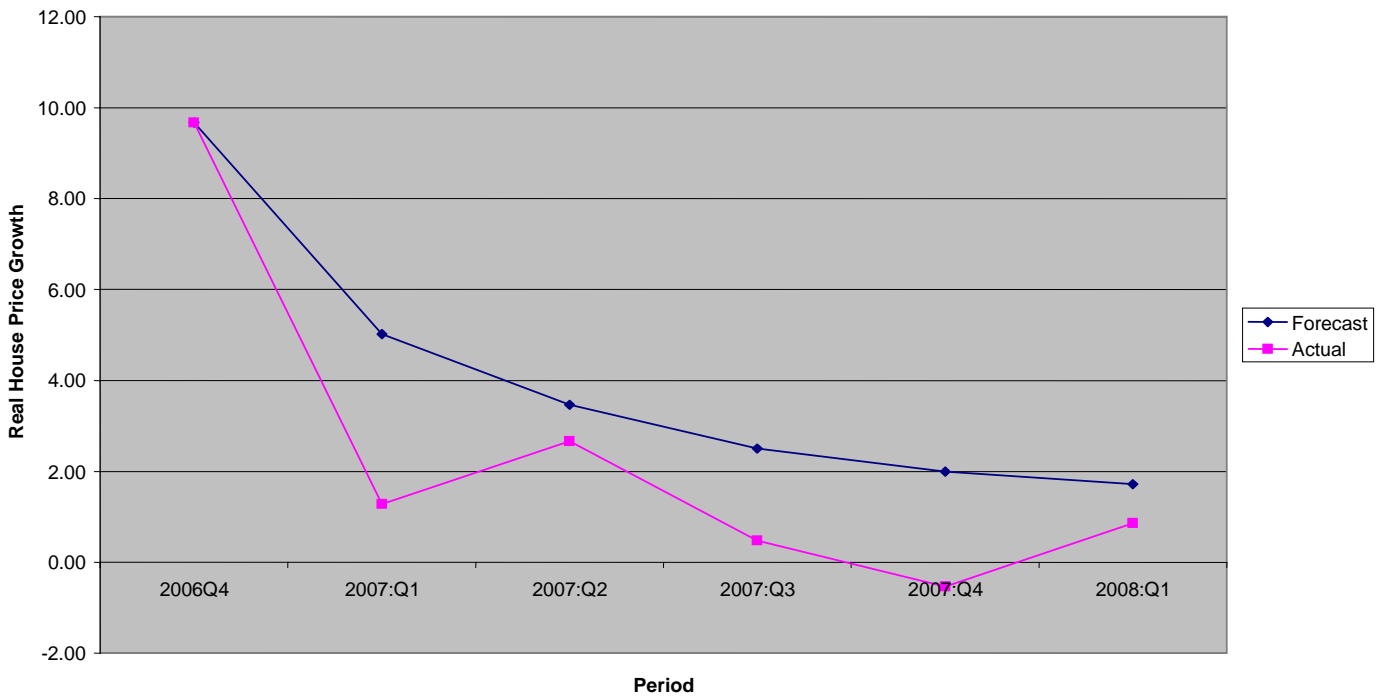


Figure 18. Predicting Turning Points for TX (2007:01-2008:01)

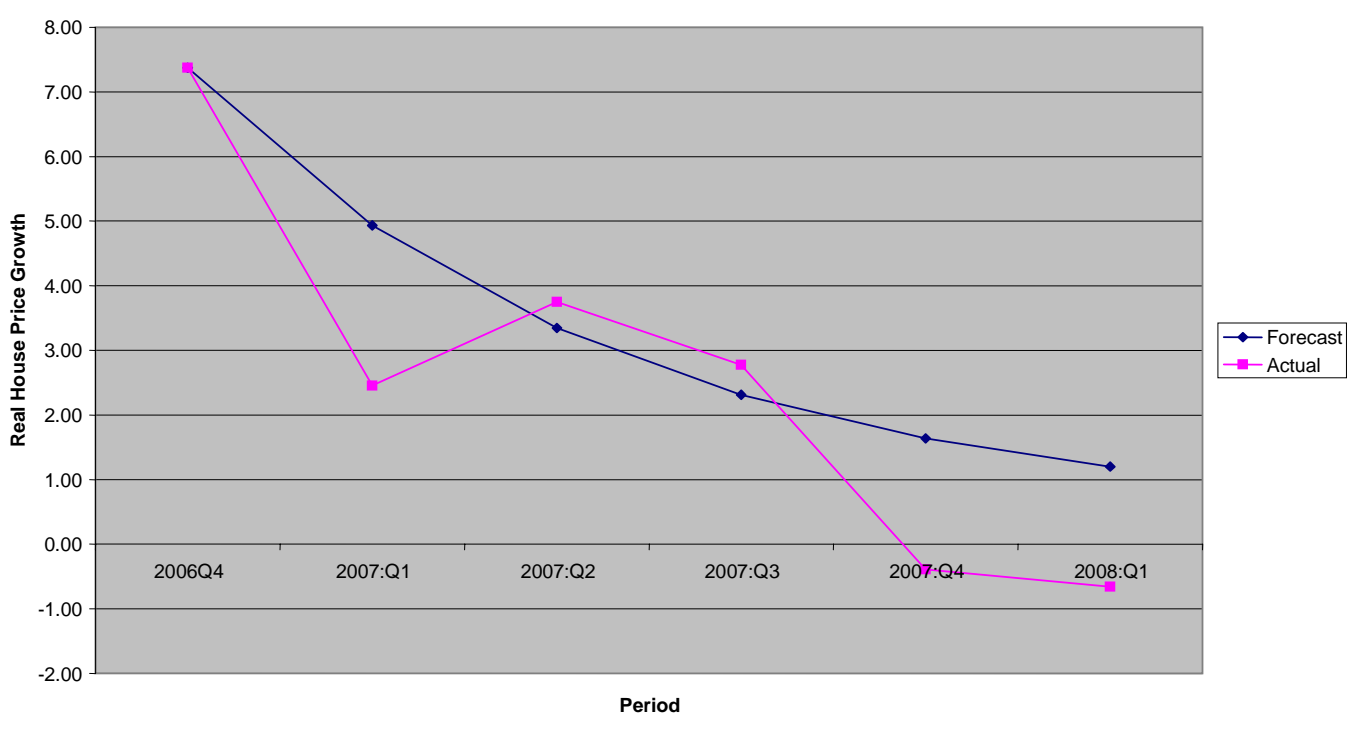

Figure 19. Predicting Turning Points for VA (2007:01-2008:01)

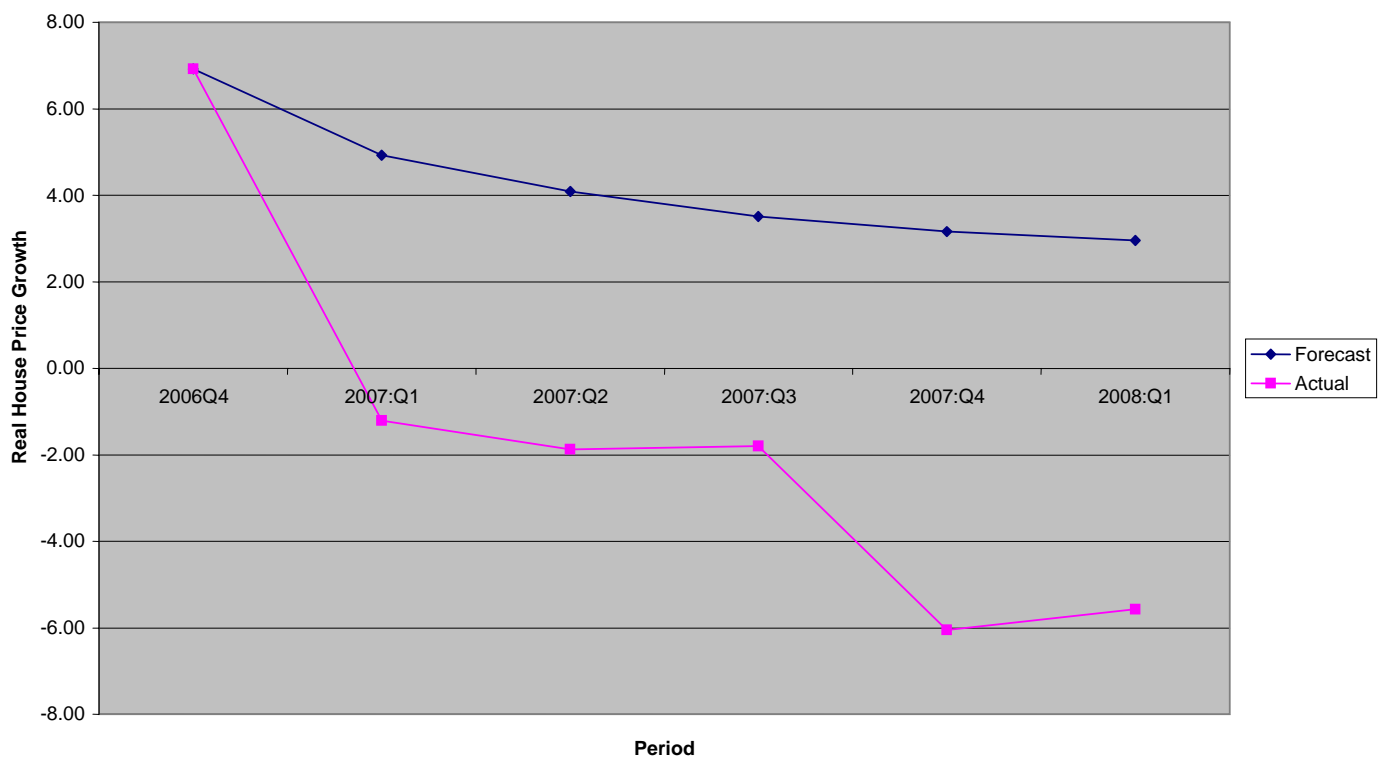


Figure 20. Predicting Turning Points for WA (2007:01-2008:01)

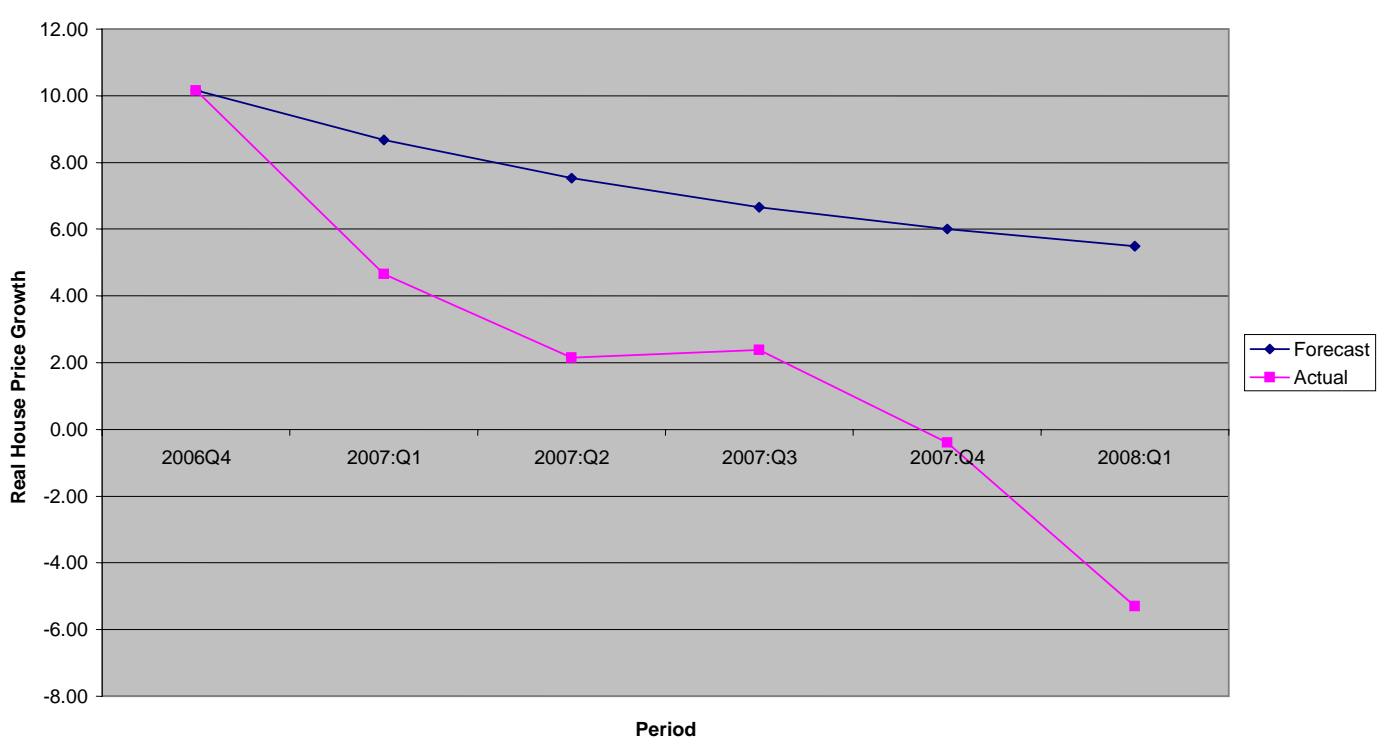

Figure 21. Predicting Turning Points for WI (2007:01-2008:01)

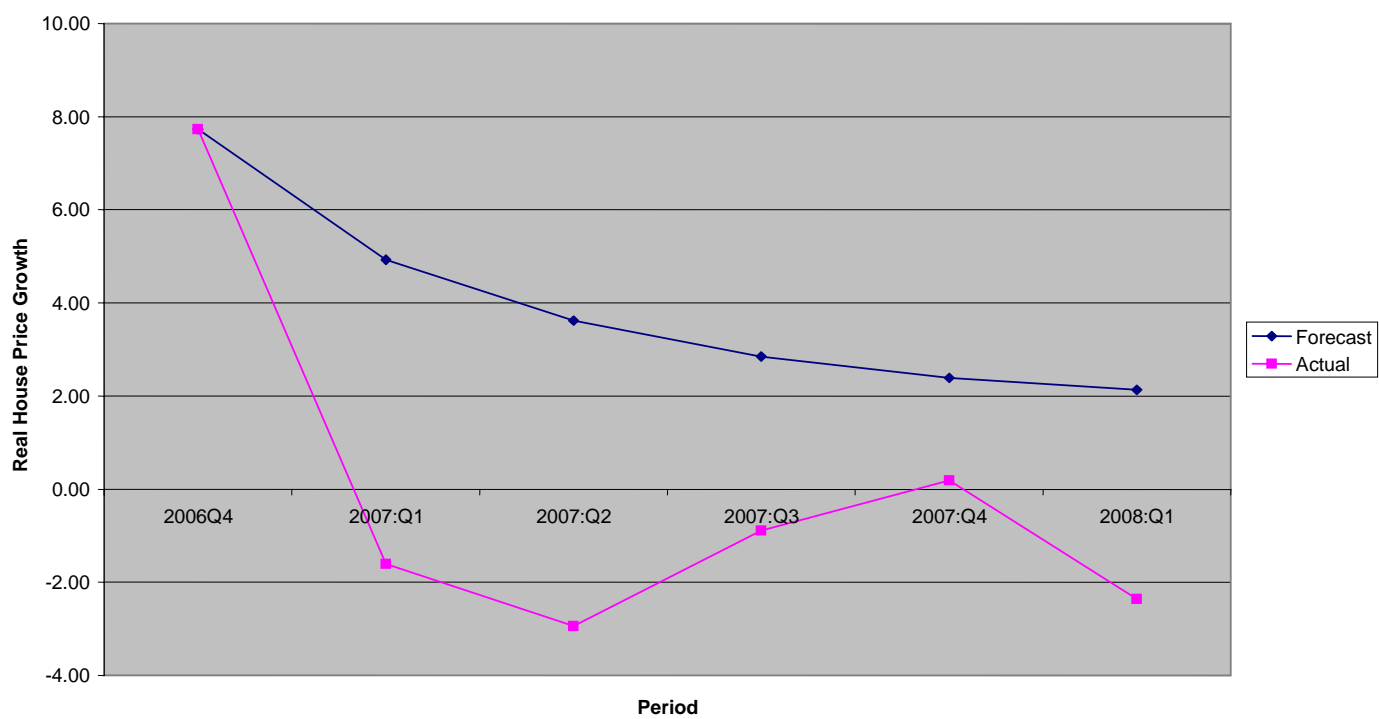

